\title{
Gamification in software engineering education: A systematic mapping
}

\author{
Manal M. Alhammad ${ }^{\mathrm{a}, *}$, Ana M. Moreno ${ }^{\mathrm{b}}$ \\ ${ }^{a}$ King Saud University, Saudi Arabia \\ ${ }^{\mathrm{b}}$ Universidad Politécnica de Madrid, Spain
}

\section{A R T I C L E I N F O}

Article history:

Received 17 November 2017

Revised 27 February 2018

Accepted 28 March 2018

Available online 29 March 2018

\section{Keywords:}

Gamification

Software engineering

Education

Systematic mapping

\begin{abstract}
A B S T R A C T
The potential of gamification in education is based on the hypothesis that it supports and motivates students and can thus lead to enhanced learning processes and outcomes. Gamification in software engineering (SE) education is in its infancy. However, as SE educators we are particularly interested in understanding how gamification is pollinating our field and the extent to which the above claim is valid in our context. A systematic literature mapping has underscored the difficulty in fully corroborating the above claim because few empirical data are available so far. However, key trends and challenges have been identified. We found that the purpose of applying gamification in the SE field is mostly directly related to improving student engagement and, to a lesser extent, to improving student knowledge, although other targets are the application of SE best practices and socialization. We have also discussed insightful issues regarding the implementation cost of gamification, patterns in the most often used gamification elements, and the SE processes and teaching activities addressed. Of the identified challenges, we should highlight the complexity of deciding which gamification approach to follow, the lack of information for choosing gamification elements and the need to control the impact of gamification.
\end{abstract}

(c) 2018 Elsevier Inc. All rights reserved.

\section{Introduction}

One of the major challenges for improving SE practice is to provide the best training and preparation for future software engineers. Efforts have primarily focused on two targets: definition and shaping of the SE curricula, and improvement of SE teaching methods and techniques. Regarding the first matter, different efforts have been made to set out and adapt the SE curricula to the contents and skills required in SE professional practice. Examples of such efforts are the standards for undergraduate and graduate SE education (i.e. the Software Engineering Education standard (SE, 2014) and the Graduate Software Engineering Education Standard (GSwE, 2009), the SE competency model (IEEE, 2014) or the compilation of expert opinions on the knowledge to be conveyed in SE education (Hazzan and Tomayko, 2005; Kitchenham et al., 2005; Lethbridge et al., 2007; Surakka, 2007; Davey and Tatnall, 2008; Grant and Helps, 2012). Alongside all these initiatives, the SE education community has also made major efforts to improve the learning process, seeking the most effective way of providing SE students with the required knowledge and skills. Alabbadi and Qureshi (2016) review different approaches used in the literature for this purpose, from traditional methods,

\footnotetext{
* Corresponding author.

E-mail addresses: manalhammad@ksu.edu.sa (M.M. Alhammad), ammoreno@fi.upm.es (A.M. Moreno).
}

such as capstone projects, to the combination of different teaching techniques, such as project-based learning, and case-based and research-based teaching. Additionally, the SE education community is also addressing other innovative pedagogical strategies like flipped classrooms (Choi, 2013), or the use of game-related approaches based on serious games or gamification (Connolly et al., 2007; Berkling and Thomas, 2013).

Gamification in particular has been considered one of the key emergent and widely adopted teaching technologies in education in this decade (Johnson et al., 2014). Gamification offers adequate solutions for the educational needs of the new generation of students (Bíró, 2014). Initially emerging in the marketing and business sectors, gamification dates back to 2008 . However, it did not experience widespread adoption until mid-2010. Gamification is usually defined as "the use of game design elements in non-game contexts" (Deterding et al., 2011). In other words, the aim of gamification is to generate or transform experiences in order to transmit similar feelings and engagement as when playing games, albeit not for entertainment purposes. The scientific study of gamification is still immature and its risks have also been highlighted. Gartner warned that about $80 \%$ of gamified applications will fail to meet business objectives, mainly because processes have been inappropriately gamified (Gartner, 2012).

In academia, the potential of gamification is based on the hypothesis that it supports and motivates students and can thus lead to enhanced learning processes and outcomes (Kapp, 2012). How- 
ever, this process is not straightforward, and it is time- and effortconsuming for educators. Additionally, there is no consistent understanding of the processes used to gamify learning activities in education (Barata et al., 2013; Borges et al., 2014; Ibanez et al., 2014). This lack of consistency has led to the failure of several gamification experiments in education, provoking undesired and unexpected effects on the learning process and learning outcomes (Domínguez et al., 2013; Li Et Al., 2013; Hakulinen and Auvinen, 2014; Hanus and Fox, 2015).

In this context, we view gamification in SE education as a research opportunity. SE educators often deal with teaching students tasks that they find repetitive, boring or demotivating. Therefore, as SE academics, we are particularly interested in understanding how gamification can be effectively used to improve SE education, that is, whether and, if so, how, gamification can support and motivate SE students and thus lead to enhanced learning processes and outcomes. The specific results to be expected from gamification, the SE educational context, the different types of courses and SE knowledge to be addressed or the particular game elements to be applied are just a few examples of challenging questions for SE lecturers and facilitators. This paper describes a systematic literature mapping on gamification in SE education aimed at exploring these and related issues. The research questions addressed will provide helpful information about the state of practice of gamification in SE education, trends and challenges.

The remainder of this paper is organized as follows. Section 2 reviews the related background in terms of gamification and its application to education and SE. Section 3 describes the research methodology followed to perform the systematic mapping, including the definition and discussion of the research questions, the search and selection processes for primary studies, the data extraction and analysis processes, as well as a discussion of the validity threats associated with this mapping study. Section 4 reports the results found. Finally, Section 5 concludes with the trends and gaps identified from our study.

\section{Background}

\subsection{Gamification}

For the past few years, gamification has emerged as a powerful technique that can be applied to different problems to influence human behavior. Initially emerging in the business and marketing sectors, gamification recently began to attract academics and educators. While there are many definitions of gamification, it all revolves around one principle, that is, the use of game elements in non-game contexts (Deterding et al., 2011). According to Deterding et al., the first documented use of gamification was in 2008, yet the idea did not gain popularity until around late 2010 to early 2011. Although the literature is sometimes misleading, gamification is not the same thing as game-based learning (GBL) and serious games. GBL deals with game applications that have defined learning outcomes (Kapp, 2012). GBL uses serious games, that is, games designed for educational purposes, hence the use of the term "serious". The key difference between gamification and serious games is that serious games refers to the design of fully-fledged games for non-recreational environments, whereas gamification refers to merely employing game design principles and elements in a particular process. We specifically address gamification, whereas GBL and serious games are outside the scope of this paper.

The major rationale for applying gamification in different domains is thought to be that gamification is motivational and has the potential to increase user engagement (Hamari et al., 2014). Gamification has been widely used in contexts such as marketing (Zichermann and Linder, 2010; Zichermann and Cunningham, 2011), healthcare (Pereira et al., 2014), sustainability
(Gustafsson et al., 2009) or innovation (Witt et al., 2011). For instance, Opower is a service that equips homes with sensors enabling residents to compare their household energy consumption with that of their neighbors (Wingfield, 2012). Nissan has set up a platform that collects points for driving ecologically, and drivers can compete with other friends on Facebook. Companies like Microsoft, IBM, Adobe and Siemens are using gamification for their main business functions and processes (Uskov and Sekar, 2014).

The benefits of gamification have been investigated by Hamari et al. (2014) who examined 24 empirical studies in different domains. Most studies claimed that gamification can have a positive impact on enhancing user motivation towards a certain behavior. However, the usefulness of gamification is dependent on the context in which it was applied. In fact, Hamari et al. reported that educational contexts tend to benefit most from gamification in terms of increased motivation and engagement. However, they also pointed out that many of the papers reviewed were descriptive, providing non-inferential data. This makes it tricky to measure the actual effectiveness of gamification objectively. Like Robertson (2010), Hamari et al. claimed that there is a need for a consistent definition of what gamification is, how gamification works and, more precisely, how to design gamified experiences that encourage the player (e.g., employee, customer, citizen) to change their behavior, resulting in desirable outcomes.

\subsection{Gamification in education}

As already mentioned, gamification has been considered as one of the emergent teaching technologies in education (Johnson et al., 2014). The academic community's interest in gamification is apparent from the number of literature reviews about gamification and education published so far. Caponetto et al. (2014) present an analysis of almost 120 papers on the topic published from 2011 to 2014 in both training contexts and formal education from primary school to higher education. They retrieved an equal number of conceptual/theoretical papers and empirical studies. As regards the studies published in the educational context, almost half of the papers are related to university courses, and a similar number are related to learning experiences performed within companies for the purpose of in-house training; they also got a few studies about gamification in primary and secondary education. Caponetto et al. also highlighted some confusion between the term gamification and game-based learning. Even though most of the studies dealt with gamification in the sense of the application of game elements in non-game environments, they also found that around $10 \%$ of the papers used the term gamification as a synonym of game-based learning or serious games. Finally, Caponetto et al. pinpointed several subject areas in which gamification has been applied, such as science, mathematics or foreign languages, although they also addressed transversal attitudes and behaviors such as collaboration, creativity and self-guided study.

Nah et al. (2014) published a literature review on gamification in education aimed at identifying what game design elements are most used in education. They analysed 19 publications that applied gamification in different contexts ranging from primary school to university. It was found that the most used game elements were points, levels, badges, leaderboards, prizes, progress bars and storytelling. They gave examples of how these elements were used in the examined gamified solutions. They concluded that there are no systematic studies assessing and evaluating the impact of gamification elements on the learning process.

Borges et al. (2014) reported a systematic mapping on gamification applied to education. They examined 26 primary studies, addressing three research questions: (1) In what educational contexts has gamification been investigated? (2) What types of studies have been published? and (3) What gamification approaches 
have been most investigated in the field of computer-supported collaborative learning? The study findings suggested that most primary studies deal with gamification for supporting higher education students, while elementary education is attracting less attention. They also found that the research aim of most studies is to evaluate the engagement of students through gamification. Finally, regarding the last research question, they found that there are few approaches combining gamification and computer-supported collaborative learning, although they suggested that this combination could be helpful for improving the outcomes of the learning process.

Dicheva et al. (2015) reported another systematic mapping study about the application of gamification to education, but they focused on published empirical studies. They retrieved 34 papers and identified the gamification principles and the gamification mechanics that they used. They found that visible status, social engagement, rapid feedback, freedom of choice and freedom to fail are the most used gamification principles, whereas badges, leaderboards, points and levels are the most common gamification elements. They also found that most of the reported case studies deal with the gamification of blended learning courses and address mostly higher education and training. Computer science/information technology is the domain most often addressed by the studies, followed by other domains such as mathematics/science/engineering. Dicheva et al. also analysed how the gamification solutions were implemented. They identified four options: (1) the development of plug-ins or extensions for the learning environment, (2) the development of specific gamification platforms, (3) manual implementation and data collection on student performance, or (4) the use of third-party software to support some aspect of gamification. They found that the first three are the most frequent options. They concluded that although proper evaluation is mostly missing, most authors agree that gamification has the potential to improve learning if it is well designed and used correctly. Higher engagement, increased attendance, and higher student participation are some of the positive outcomes identified. Some weaknesses were also detected related, for example, to missing critical motivational elements, outcome sensitivity to small changes in the gamified solution, or the time and cost of applying gamification. Dicheva et al. also stated the need for more substantial empirical research to investigate the motivational effects of using single game elements in specific contexts and for particular learners.

Finally, Souza et al. (2017) conducted a systematic mapping of the application of game-related methods in the field of SE education. From their 106 primary studies, they found that eight were related to gamification, whereas the remainder were similarly distributed between GBL approaches (using games as instruments to support education (Kapp, 2012)) and game development based learning (a learning approach that requires students to develop a game on the basis of a game development framework ( $\mathrm{Wu}$ and Wang, 2012). Additionally, they discussed which SE knowledge areas are usually addressed by game-related methods, finding that the software process is predominant in GBL, whereas software design is frequently used in game development based learning. In their sample, gamification studies did not generally deal with these specific areas, as the papers found mostly focused on promoting engagement and fun to keep students motivated during lectures without focusing on gamifying any specific topic. One of Souza et al.'s conclusions is that the application of gamification in SE education is an open field of research.

\subsection{Gamification in software engineering}

Although not focused on education, the particular case of gamification and SE is worth mentioning, as SE education ultimately deals with teaching SE processes. SE practice entails the enactment of different processes that are considered repetitive and time consuming, like bug hunting, code reviews, requirements elicitation or change management. Far from being considered creative, some of these tasks are even considered as "destructive", and are, therefore, not very attractive. Consequently gamification can be a promising strategy for potentially enhancing developers' interest and motivation in carrying out these SE tasks (Khandelwal et al., 2017).

Some examples of gamification applied to the SE domain are to be found in the software construction area, including proposals like de Melo et al.'s, which automatically extracts information from version control systems and analyses the changes introduced by each developer in order to reward the more productive teams (de Melo et al., 2014). In the requirements engineering area, Fernandes et al. (2012) described a collaborative requirements elicitation environment in which a point-based system is used to reward the participants for carrying out actions such as registering a new requirement, scoring existing requirements or commenting on requirements to clarify their meaning for stakeholders. Other domains where gamified solutions are to be found are project management, where Bacon et al. (2012) proposed a model in which the project manager and the developer responsible for the task are rewarded according to a point-based system, depending on the accuracy of the estimations and real results.

Pedreira et al. (2015) recently published a systematic mapping on gamification in SE. Their aim was to analyse the existing proposals and research work in this area. They retrieved 29 papers discussing gamified solutions in the SE domain and found that studies focusing on gamification applied to SE date back to 2011. They explicitly excluded studies whose primary objective was to gamify education. They highlighted that gamification in SE is still at a very early stage with little evidence about its effect. They discussed the shortage of sound evidence on the impact of gamification in SE practice and recalled the risk of "lemmingineering", that is, following a path just because everybody is doing it (Davis, 1993). In fact, they pointed out that, although most of the studies apply traditional game components, such as points, levels and badges, there is no evidence about which of the mechanisms is most suitable. Besides, there are no studies focusing on the most suitable dynamics for taking advantage of the respective mechanics to engage and motivate players. In this respect, Pedreira el al.'s results for the field of SE are consistent with the existing literature on gamification. As regards the gamified SE processes, the mapping shows that software implementation is the area on which most studies focus, followed by software requirements, and a few experiences in other areas like project monitoring and control, or collaboration. However, Pedreira et al. highlight that methodological support, that is, a systematic process for applying gamification in the above process areas, is largely missing. In response, they very recently published another paper with a specific process for gamifying SE practices (García et al., 2017).

\section{Research methodology}

We employed a systematic mapping approach to conduct our study. To do this, we followed the guidelines and recommendations of Petersen et al. (2015). The study was conducted during the first half of 2017 and covers publications about gamification in SE education from 2011 until June 2017.

\subsection{Research questions}

Table 1 outlines the research questions used in this systematic mapping. Beyond identifying the potential benefits of gamification, these questions should offer SE academics a snapshot of the field, as well as enabling them to identify and analyse current trends and 
Table 1

Research questions.

\begin{tabular}{ll}
\hline ID & Research question \\
\hline RQ1 & In which context of SE education has gamification been applied? \\
& RQ1.1. What types of SE course have been gamified? \\
& RQ1.2. Which educational activities have been gamified? \\
RQ1.3. Which software engineering processes have been gamified in education? & \\
RQ2 & $\begin{array}{l}\text { How has gamification been implemented in SE educational courses? } \\
\text { RQ2.1. What processes or approaches, if any, have been followed to incorporate gamification in SE education? } \\
\text { RQ2.2. What gamification elements/components have been used? } \\
\text { RQ2.3. What kind of tools/instruments have been used to implement the gamified solution? }\end{array}$ \\
RQ3 $\quad$ What is the evidential impact of gamification on SE education?
\end{tabular}

gaps. The goal behind RQ1 is to understand the educational setting in which gamification has been applied. We specifically deal with three issues to describe this scenario: the type of SE courses that have been gamified, that is, whether gamification efforts target online courses, blended courses, etc.; the educational activities that have been gamified, for example, software projects, traditional lectures, etc.; and, finally, the SE processes that are most often addressed, i.e., software testing, requirements, configuration management, etc.

RQ2 focuses on discovering how gamification was put into practice. Again, this question addresses three aspects: the different approaches and methodologies followed to gamify SE education; the gaming elements that were combined to gamify SE education; and the tools, if any, that were used to apply gamification to the respective SE courses. A SE instructor who plans to use gamification has need of this information to decide whether to use an existing gamification method or design a new gamification approach based on the gaps and weaknesses of current solutions. Information about the technical support (tools) needed to gamify a SE course also provides key data about the cost of gamification, as well as which of all the gamification components existing in literature have been used (Werbach and Hunter, 2012). Finally, RQ3 deals with the existing evidence on gamification effects in SE education; in particular, the purposes for which SE education has been gamified and what evidence there is about the results. This information will be useful for discovering whether gamification in SE education has had both positive and/or negative effects on the SE learning process and outcomes.

\subsection{Search process}

The search process followed in this study is outlined in Fig. 1 and was conducted during the first half of 2017. The search string was composed of three major terms: gamification, software engineering, and education. Each term was then refined into multiple synonymous terms. For the term "gamification", we, like other literature reviews on gamification (Hamari et al., 2014; Pedreira et al., 2015) considered the keywords: gamifying, gamified, gamify, and gamification. Other terms like "gameful" and "funware" were not added to the search string because they introduced many irrelevant search results, especially in the field of serious games and game-based learning, which are outside the scope of this study. As for the term "software engineering", we adopted the approach outlined by Pedreira et al. (2015) and used the keywords shown in Fig. 1 in accordance with the software processes defined in ISO/IEC 12207. For the third part of the search string, Fig. 1 shows the synonyms used for "education", which are consistent with other systematic mapping studies in education such as (Qadir and Usman, 2011) or (Marques et al., 2014). Finally, the search terms were
Table 2

Summary of search results.

\begin{tabular}{ll}
\hline Database & Search results \\
\hline ACM & 17 \\
IEEE & 24 \\
SCOPUS & 88 \\
ScienceDirect & 1 \\
Web of Science (core collection) & 25 \\
Web of Science (inspec) & 32 \\
Backward snowballing search & 5 \\
Total & 192 \\
Total without duplicates & 132 \\
\hline
\end{tabular}

then linked using the logical operator "AND" for the three major parts of the search string and "OR" for synonymous keywords.

We selected IEEE, ACM, SCOPUS, Web of Science (core collection), Web of Science (Inspec), and ScienceDirect as our primary sources based on the recommendation of Petersen et al. (2015) and the search string was applied on meta data. To remove duplicates and manage search results, we used the Mendeley reference management tool (Mendeley, 2017). Table 2 shows the search results per database. We also applied backward snowballing in the search for primary studies, that is, we tracked and scanned the references of papers marked as potentially relevant in search of other relevant studies.

\subsection{Study selection process}

The selection process of primary studies was composed of two screening stages. During the first stage, the titles and abstract were read to measure relevance. During the second stage, the full text was read to make a decision on inclusion or exclusion. To avoid the premature exclusion of studies, doubtful studies were always included for further and detailed reading during the second stage.

In general, we are interested in studies that gamify SE education. More specifically, the following inclusion and exclusion criteria were defined:

Inclusion criteria:

1. Studies dealing with gamification AND

2. Studies dealing with SE education.

Exclusion criteria:

1. Studies gamifying SE rather than SE education, or studies gamifying courses not related to ISO SE processes.

2. Studies dealing with serious games or game-based learning or not explicitly using gamification (see Section 2.1, for the definitions of these terms).

3. Studies whose full-text is not accessible. 


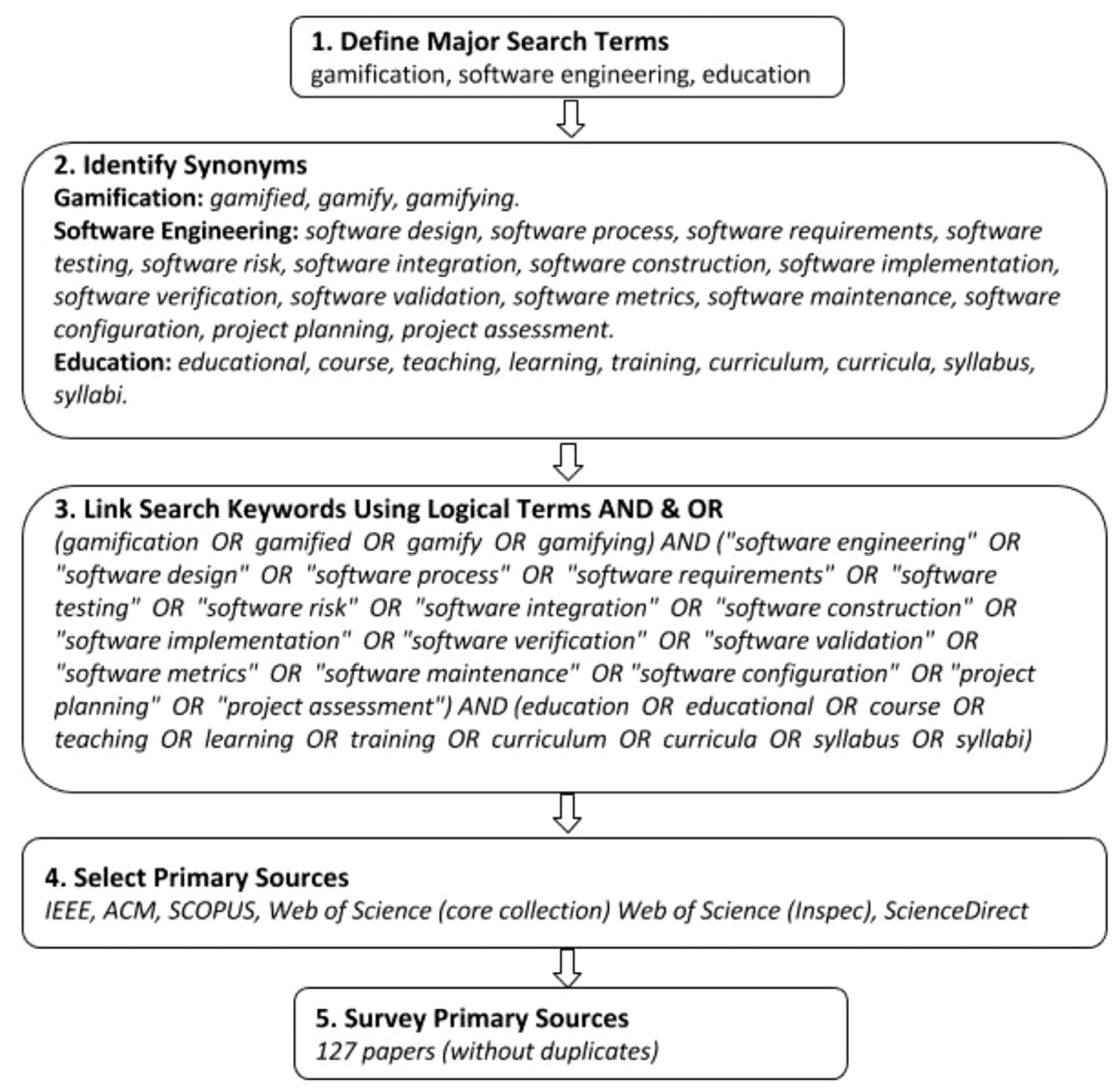

Fig. 1. Search Process.

4. Studies not written in English.

5. Studies that are summaries of other studies.

6. Panel studies or summaries of conferences.

In the first stage, the first author scanned a total of 127 studies retrieved by the database search process (after removing duplicates). As a result, 40 papers were marked as potentially relevant based on reading titles and abstracts. The second author screened all the potentially relevant studies and initially agreed on $93 \%$ of the studies (37 papers). A discussion regarding the other three papers led to the decision to include all of them for a thorough full-text reading in stage two. Furthermore, the second author reviewed a random selection of $30 \%$ of the 87 excluded papers from stage one to confirm that both researchers had interpreted the exclusion criteria consistently and prevent potentially relevant papers from being left out. The second stage involved both authors applying the selection criteria after reading the full text of the papers selected in Stage 1. This stage also included the backward snowballing process after tracking the references of the 40 papers from Stage 1 . As a result, a total of 21 papers (see Appendix A) were included, 19 papers from the database search and two papers from backward snowballing. To increase the reliability of the Stage 2, the authors discussed each of the 42 papers (40 from Stage 1 plus 2 from the snowballing process) and together decided to include the 21 papers. During both stages, we recorded the rationale for excluded papers, as shown in Table 3.

\subsection{Data extraction process}

The data extraction process was divided into three major steps: design of data extraction form, data extraction, and validation of extracted data. The data extraction form, illustrated in Table 4, was designed following guidelines by Petersen et al. (2015) and also includes the RQ to which each field contributes. The key fields are:

- Research Type: The following classifications were adapted from Petersen and Feldt (2008) and Wieringa et al. (2006) to the education field in order to record the type of research reported in the primary studies:

- Evaluation research: A study reporting gamification applied in a SE course, where evaluation is conducted in a real setting (i.e., classroom).

- Validation research: A study reporting gamification applied in a SE course where the gamified solution was validated in a laboratory setting (e.g., a pilot study, experiment with volunteer students).

- Solution proposal: A study proposing a gamified solution for a SE course that was neither evaluated in a real setting nor validated in a laboratory environment.

- Experience paper: A study reporting the authors' experience, reflections, benefits and drawbacks of gamifying SE education.

- Philosophical papers: A study describing a new conceptual idea, implying a new way of gamifying SE education. 
Table 3

Rationale for excluded studies.

\begin{tabular}{ll}
\hline Reason & Frequency \\
\hline Duplicates & 60 \\
Not in the SE education/training context & 56 \\
Use of game-based learning or serious games or no explicit use of gamification & 20 \\
Full text not accessible & 12 \\
Not written in English & 1 \\
Panels or summary of conferences & 21 \\
Studies that are summary of other studies & 1 \\
& \\
Total retrieved & 192 \\
Total included after study selection Stage 1 & 40 \\
Total included after study selection Stage 2 & 21 \\
Total excluded & 171 \\
\hline
\end{tabular}

Table 4

Data extraction form.

\begin{tabular}{|c|c|c|}
\hline Data item & Value & RQ \\
\hline Study ID & First author's last name + year of publication & \\
\hline Article Title & Name of the article & \\
\hline Author Name & Names of all the authors & \\
\hline Year of Publication & Calendar year & \\
\hline Venue & Name of publication venue & \\
\hline Type of Research & Evaluation research, solution proposal, validation research, experience paper, philosophical paper, or opinion paper. & \\
\hline Type of Course & What is the type or format of the gamified course? & RQ1.1 \\
\hline Gamified Activities of SE Education & Which SE education activities/components have been gamified? & RQ1.2 \\
\hline SE Process & Which software processes according to ISO/IEC 12207 are addressed by gamification? & RQ1.3 \\
\hline Gamification Approach & If identified, what approach or method is followed to gamify SE education? & RQ2.1 \\
\hline Gamification Elements & Which gamification elements, mechanics, and dynamics are used in the paper? & RQ2.2 \\
\hline Type of Implementation & How has gamification been applied? What tools or platforms were developed or used, if any, to support the gamified experience? & RQ2.3 \\
\hline Purpose of Applying Gamification & What is the aim of gamifying the SE course/curriculum? & RQ3 \\
\hline Impact of Applying Gamification & Was the impact of applying gamification in SE education positive, negative, or neutral? & RQ3 \\
\hline Notes & Any special notes that the authors want to record for each study & \\
\hline
\end{tabular}

- Opinion paper: A study reporting the authors' opinion about applying gamification in SE education rather than describing a new result of applying gamification in SE education, a novel design, or a conceptual idea.

- Type of SE course in which gamification was applied, that is, whether the gamified SE course was a traditional course with no online support, an online course, a blended learning course, or other.

- Gamified educational activity, that is, the type of educational activity, such as projects, assignments, lectures, etc. that has been gamified.

- SE processes, categorized according to the ISO/IEC 12207 classification for software lifecycle processes: software design, software process, software requirements, software testing, software risk, software integration, software construction, software implementation, software verification, software validation, software metrics, software maintenance, software configuration, project planning, project assessment.

- Gamification approach, recording the different methods and approaches, if any, followed to gamify a SE course. We defined a gamification approach as the series of steps or actions taken in order to gamify a SE curriculum or course.

- Gamification elements, recording the gamification dynamics, mechanics, and elements used in primary studies as part of the gamified SE curriculum or course.

- Type of implementation, recording the supporting tools or platforms, if any, that were developed or used as part of the gamified experience.

- Purpose of applying gamification, recording information about the aim or reason behind gamifying a SE course, that is, do the authors want to improve student performance, motivation, etc.
- Gamification impact, gathering information regarding the evidenced effect of applying gamification in SE education.

After re-reading the full text of the primary studies, we captured text segments from the original papers and reasoned some other important details into the data extraction process. By "reasoned", we mean that the answer to some research questions may not be a straightforward piece of text. In these cases, we had to summarize some information from the context. For example, the gamification elements used in primary studies are generally a straightforward piece of information. On the other hand, we very often had to understand and summarize different parts of the paper to extract and outline the gamification approach followed, as this was not as straightforward as highlighting a piece of text.

\subsection{Analysis process}

To analyse the data extracted from Section 3.4, we employed the thematic analysis steps following the guidelines by Cruzes and Dyba (2011) using NVivo 11 as a supporting tool. Fig. 2 illustrates these steps. First, we extracted the necessary data for our analysis using the data extraction form. Then important segments were coded using a convenient labelling system for the research questions. For example, text segments referring to the gamification approach followed in primary studies were coded as "approach" and were linked with RQ2.1. We used NVivo to create a "node" for each code and then placed all relevant text segments under the appropriate node. This gives a clear picture of all text segments from all primary studies associated with a particular code. This should facilitate the process of observing themes and patterns.

We coded the entire dataset. We then started identifying themes for the collected data related to each code. For example, all segments of texts coded as "approach", representing information 


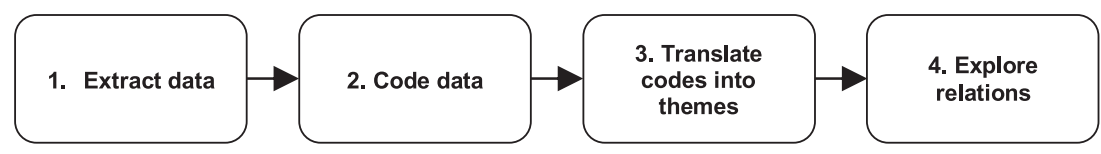

Fig. 2. Thematic analysis process.

related to RQ2.1, were analysed separately looking for patterns and themes. The themes identified in this step served as classification categories for each research question as discussed in the following section.

The next step was to search for connections or relations between themes and compare themes across different studies. For example, we wondered whether there was a connection between the gamification approach followed or the technological solution used, and the impact of gamification.

\subsection{Validity evaluation}

It is important to discuss validity threats as a quality criterion. Accordingly, following the guidelines provided by Petersen et al. (2015), we identified and mitigated the following three threats.

Search Coverage: This threat concerns the completeness of the search process and the preventive measures taken to avoid leaving out relevant studies. To reduce this threat, we took different actions. First, we designed a search string that was as comprehensive as possible, while limiting the keywords to the scope of the study. To identify the synonyms of the major search terms, we referred to previous mapping studies within the field of SE, gamification, and education. Then, we applied the search string on several different scientific databases and indices to make sure that the coverage was exhaustive. On the other hand, this mapping study only included papers whose authors use the concept of gamification in terms of using game elements for non-game contexts, in this case SE education. This decision was helpful for excluding papers dealing with game-based learning or serious games, which are outside the scope of this study. However, we might have missed some papers that use game-based-learning or similar terminology to refer to gamification ideas. All systematic mappings about gamification that we have found in literature are open to this threat; it would have been extremely costly to check all papers under the game concept.

Study Selection: This threat concerns the possibility of researcher bias and author disagreement on exclusion and inclusion. We applied two strategies to deal with this threat. First, both authors defined clear inclusion and exclusion criteria, which they discussed to reach a common understanding of each criterion. This method reduced the threat of author disagreement as they had a coherent list of criteria to refer to in the event of discrepancy. Since the study selection process was primarily performed by the first author, there was a threat of researcher bias. Hence, the second strategy for dealing with threats with respect to the study selection process was to have the second author review the selection process. Therefore, the second author randomly selected and checked $30 \%$ of the excluded studies to assess the validity of the first author's decisions.

Data Extraction: This threat refers to the likelihood of authors extracting and interpreting data differently. Again researcher bias is a possible threat to the data extraction process. To reduce this threat, the designed data extraction form included a clear definition of each data field, which the authors discussed to assure a common understanding. Additionally, the data extraction process was performed by the first author and then reviewed and validated by the second author. The review process consisted of either adding or correcting specific contents in the data form, or adding comments regarding the clarity of the extracted data. This review process was highly beneficial in terms of extracting implicit data,

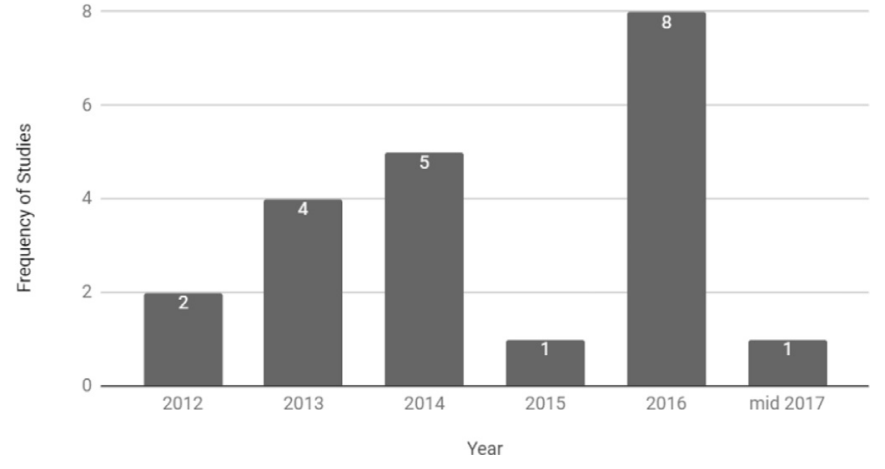

Fig. 3. Distribution of primary studies by year.

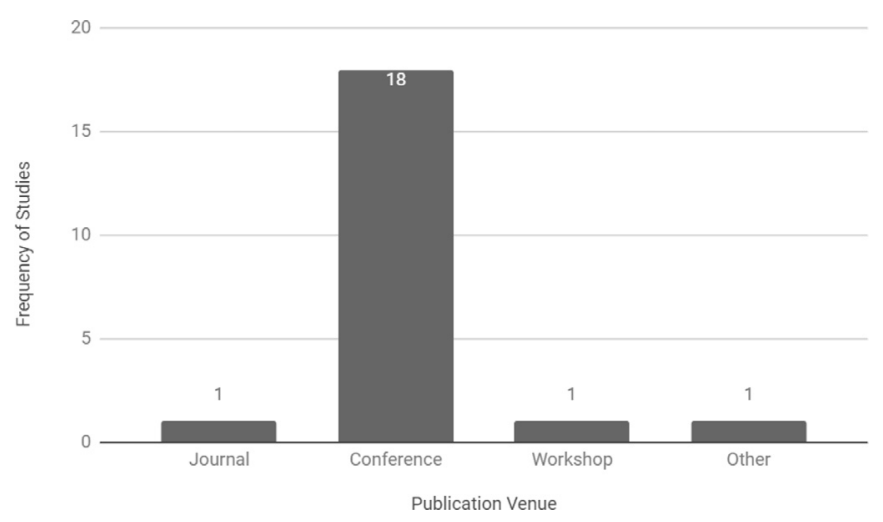

Fig. 4. Distribution of primary studies by publication venue.

and it provided a better understanding and representation of the extracted data.

\section{Results}

\subsection{General results}

This section reports the general descriptive data gathered from our study. Fig. 3 shows the distribution of primary studies according to their publication year. The first two primary studies that applied gamification in SE education date back to 2012. The number of published studies increased in the following years, with four studies published in 2013, and five studies published in 2014. However, the numbers dropped to only one published study in 2015, rising again sharply to peak in 2016 with eight published studies. Finally, only one study was published in the first half of 2017. As we are working with a short time frame, it is not easy to conclude a trend. However, even considering that the number of papers by mid 2017 is low, the interest in the area appears to have been growing over recent years.

Fig. 4 shows the distribution of primary studies by publication venue. We find that conference papers, 18 out of the 21 primary studies, are clearly dominant, whereas only one paper was published in a journal. The other two papers were published at workshops or other formal meetings. The fact that there are hardly any consolidated publications in journals is a clear indicator of the immature status of gamification in SE education to date. 


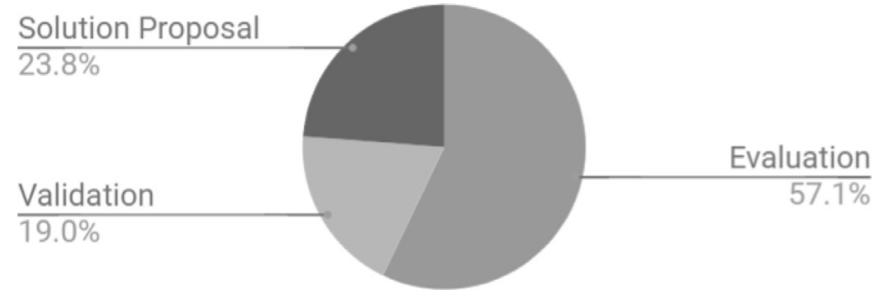

Fig. 5. Distribution of primary studies by research type.

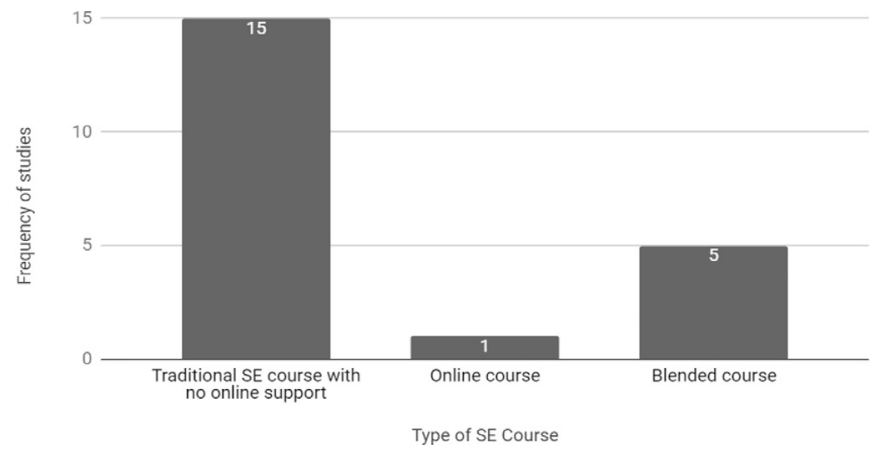

Fig. 6. Distribution of primary studies by the type of gamified course.

Fig. 5 shows the distribution of primary studies according to the research method they followed (Table B.1 in Appendix B provides a detailed mapping of each primary study to its research type). Fig. 5 shows that all primary studies fall into the solution proposal, evaluation research, or validation research categories. The results also indicate that most of the publications (around 77\%) provide an assessment of either their own gamification solution or another gamification solution proposed elsewhere. More than half of the primary studies, 12 (57.1\%) out of 21 , conducted evaluation research (i.e., in a real classroom setting), whereas four papers (19\%) conducted validation research (i.e. in an organized laboratory setting). Finally, only five papers (23.8\%) proposed a solution technique to gamify a SE course but the solution was neither evaluated nor validated.

\subsection{RQ1 - Context of application}

RQ1 addresses the scenario of SE education in which gamification was applied. As mentioned above, we dealt with the following three aspects: the type of SE course, the SE educational activity in which gamification was applied, and which part of the SE process was gamified.

\subsubsection{RQ1.1 - Course type}

RQ1.1 aims to identify the different types of SE courses in which gamification was applied. As illustrated in Fig. 6, it was found that most studies (15 primary studies) applied gamification in a traditional SE course. Traditional course refers to a course that does not provide online support for any part of the learning process. Only one paper presented a gamified SE course that was completely online, and five studies reported their experience with gamifying a blended learning course. In the case of blended learning courses, we observed that the gamified part of the course was always the online/digital part. Chirila et al. (2016), for example, gamified the use of online tutorials through a web application prototype, whereas Fu and Clarke (2016) gamified the use of online tutorials in their own online learning platform. Table B.2 in Appendix B lists the paper references for each course type.

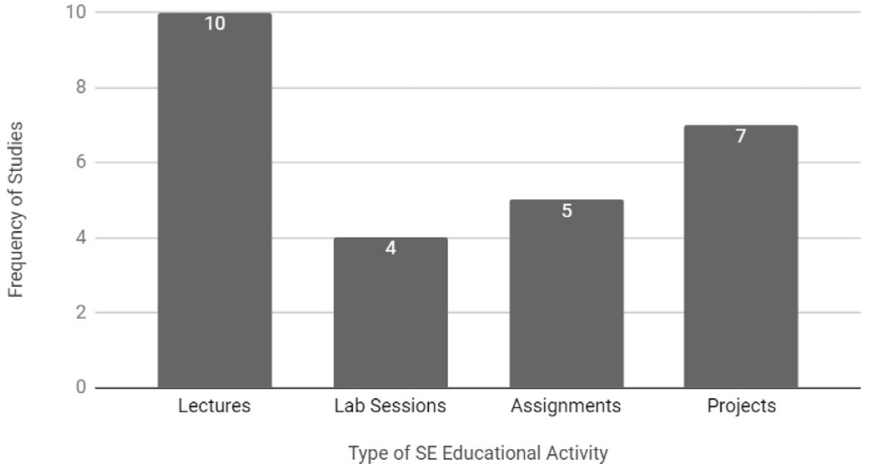

Fig. 7. Distribution of primary studies by the gamified educational activity.

\subsubsection{RQ1.2 - Educational activity}

RQ1.2 deals with the teaching activity that was gamified. The data analysis led us to group the papers under the following four categories:

a. Lectures: studies that gamified the lecture or the way of delivering/teaching the course material.

b. Lab sessions: studies that gamified in-class or in-lab practical activities.

c. Assignments: studies that gamified any out-of-class assignment or homework.

d. Projects: studies that gamified projects where students practise classical software development process activities.

Fig. 7 plots the distribution of primary studies according to these categories (Table B. 3 in Appendix B contains the specific references in each category). The results show that lectures were the most gamified component of SE courses, accounting for ten primary studies, followed by projects, assignments and lab sessions.

The SE lectures were gamified in different ways. For instance, Berkling and Thomas (2013) gamified the learning of basic SE concepts by giving students some tasks related to different SE subjects and tracking their progress through an online interactive tool. Other papers, such as Bartel and Hagel (2014), gamified only part of the lecture by challenging students during lecture time with mobile-based quick quizzes about the basic SE concepts that they have learned. Moreta et al. (2016) used another approach, delivering a tool to support the teaching process of a risk management course by presenting the students with different scenarios to identify, analyse, and mitigate risks.

Students' projects were also gamified in different ways, although most papers focus on creating competition and reward. Dubois and Tamburrelli (2013), for example, gamified students' projects by awarding students with points for fulfilling the functional requirements of their projects as well as providing high quality code (for which they used several metrics such as lines of code, test coverage, and duplication). On the other hand, Singer and Schneider (2012) rewarded the student with the highest number of commits to version control by listing his/her name at the top of a leaderboard, thus adding a sense of competition and accomplishment to students' projects.

Regarding out-of-class assignments, we found that "quest" is used in several papers to represent such assignments. For example, Matsubara and Silva (2017) engaged students to complete assignments by awarding students experience points for each quest (i.e., assignment) they solved, as well as providing them with immediate feedback on how well they did in the quest. Similarly, Mora et al. (2016) motivated students to solve non-graded assignments by presenting these tasks as "quests" with different progress stages: onboard, midgame, and endgame. Other approaches than quest were also adopted. For example, Uskov and Sekar (2014) set 


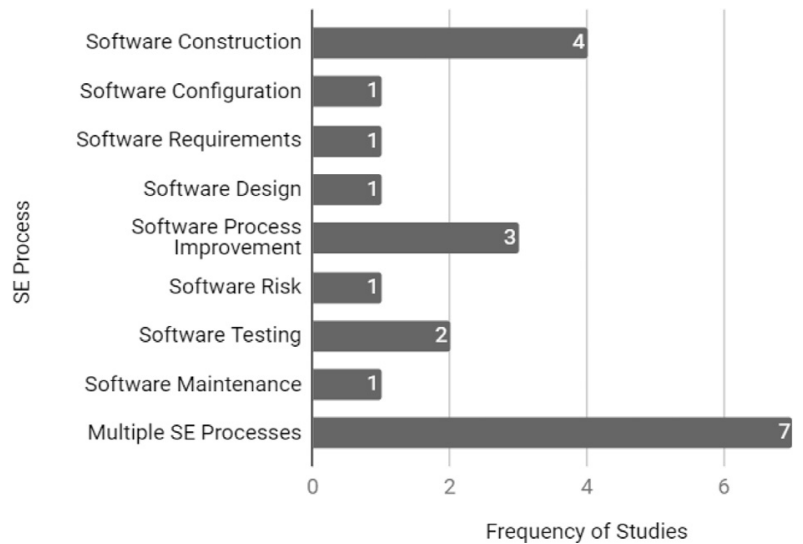

Fig. 8. Distribution of primary studies by the addressed SE process.

students two or three optional assignments, on top of compulsory assignments, to earn extra marks.

Finally, the approaches used in primary studies for gamifying lab sessions were not very different to the quests used to gamify assignments. For instance, Bartel and Hagel (2016), gamified the learning of design patterns using quests solved by students in groups during the lab session. Moreover, Fuchs and Wolff (2016) gamified lab sessions by giving students Java programming challenges to solve as a group. In their gamification approach, they used a supportive tool where groups are able to see their progress in a particular challenge and the points they earned in each challenge.

\subsubsection{RQ1.3 - SE processes}

RQ1.3 aims to identify the SE processes that the primary studies addressed. As discussed previously, we account for the processes defined in ISO/IEC 12207. Fig. 8 shows the frequency of primary studies distributed by SE processes. Further details about the specific primary studies in each category can be found in Table B.4 in Appendix B.

Since our study focuses on SE in the context of education, quite a high percentage of the primary studies (seven papers) dealt with multiple SE processes reflecting a typical SE course that addresses several topics, mainly requirements engineering, software design and software testing processes, as reported by Berkling and Thomas (2013) or Bartel and Hagel (2014).

For the studies that deal with a specific SE process, software construction was found to be the most gamified SE process. Under this category, we included papers dealing with gamifying the learning of programming. For example, Fuchs and Wolff (2016) and Ibanez et al. (2014) gamify the learning of specific programming languages (Java and C, respectively). Some primary studies did not deal with a specific programming language but rather gamified the learning of general programming principles. This is the case of Kheirkhahzadeh et al. (2016) who focus on functional programming, or Chirila et al. (2016) who deal with algorithm design.

Another interesting category is software process improvement, which includes papers that modify a software development process by incorporating SE best practices while adding gamification elements. This modified software process is generally applied in students' projects with the aim of encouraging students to adopt SE best practices. For instance, this is the case of Dubois and Tamburrelli (2013), who gamified an object-oriented development process to encourage design quality, test coverage and bug reports, or Akpolat and Slany (2014), who gamified the use of extreme programming practices.

Software testing is another process where more than one paper was found (Sheth et al., 2013; Fu and Clarke, 2016). Fu and

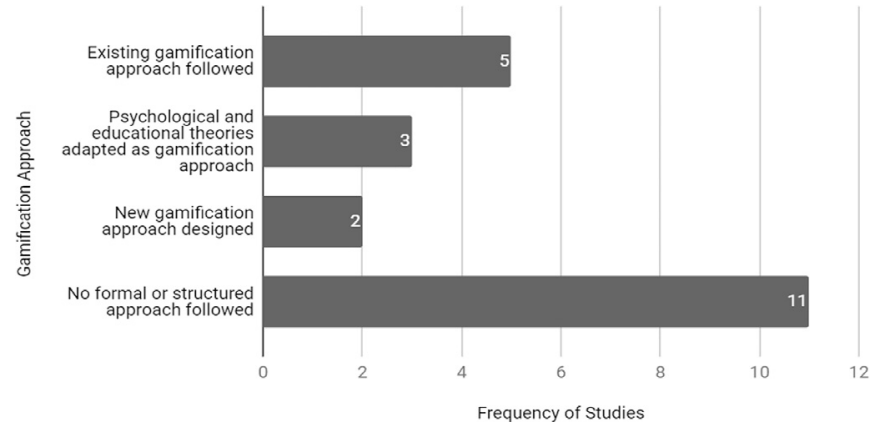

Fig. 9. Distribution of primary studies by gamification approach followed.

Clarke (2016) provided students with an interactive tool that offers several tutorials on basic software testing concepts and rewards students for completing these tutorials. Sheth et al. (2013), on the other hand, focus on gamifying the learning of standard software testing techniques like white and black box testing, unit testing, and boundary value analysis using the existing online gamified tool called "HALO" .

\subsection{RQ2 - Implementation of gamification}

The aim of RQ2 was to understand how gamification was implemented in a SE curriculum. Thus, we collected data about the following three aspects: the gamification approach; the gamification elements used during such process; and the kind of tools used.

\subsubsection{RQ2.1 - Gamification approach}

RQ2.1 outlines the different approaches and methods that were used in primary studies to gamify SE courses. Throughout the data analysis process, four categories of gamification approaches were identified:

1. An existing gamification approach was used: this includes studies that follow an existing gamification framework that was proposed or designed by someone else.

2. A psychological or educational approach was adapted as a gamification approach: this includes studies that tailored motivational or educational theories to gamify a SE course or educational activity.

3. A new gamification approach was proposed, designed and followed: this includes studies that design their own structured, step-by-step, methodology to gamify a SE course.

4. No formal or structured process was followed: this includes studies that do not follow a defined method to integrate gamification into a SE course.

Fig. 9 shows the distribution of primary studies by the type of approach followed to gamify SE course/curriculum (see Table B.5 in Appendix B for details). We found that there were a similar number of studies that followed a particular approach (existing approach, psychology-based approach or new approach) versus studies that did not follow any structured approach. The group of studies that did not follow a structured approach to incorporate gamification include papers that: 1) experiment with gamification by incorporating a selection of gaming elements in a SE educational activity, or 2) create a gamified solution based on the literature of gamification. For instance, the study by Laskowski (2015) is an example of option 1), conducting two different experiments using two different sets of gamification components. While Buisman and van Eekelen (2014) is an example of option 2), analysing the gamification literature and applying a selection of the most used game elements. 
15

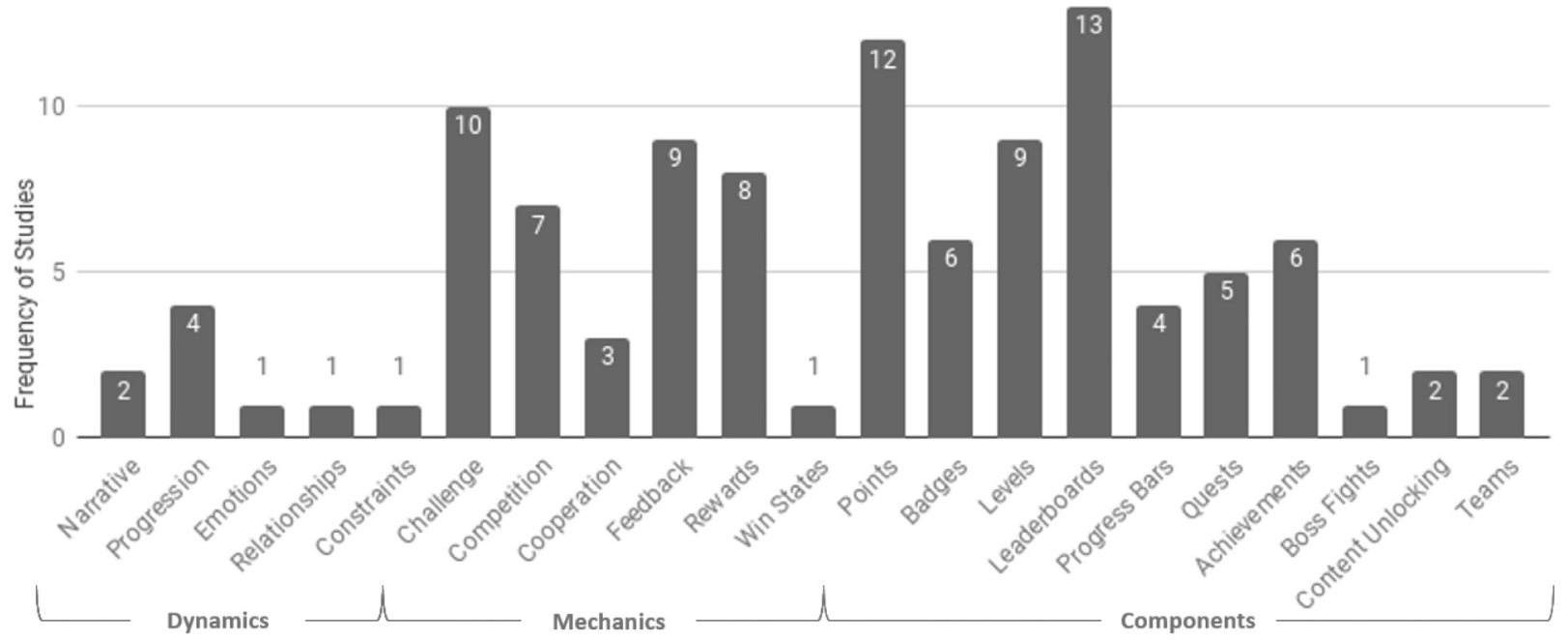

Gamification Dynamics, Mechanics \& Components

Fig. 10. Distribution of primary studies by gamification dynamics, mechanics, and components.

Of the papers that followed a structured approach of gamification, five papers followed an existing gamification method to gamify their SE courses. For example, Bartel and Hagel (2016) and Moreta et al. (2016), adopted the gamification design elements framework proposed by Werbach and Hunter (2012), while Mora et al. (2016) followed a gamification approach based on MDA (mechanics-dynamics-aesthetics) (Hunicke et al., 2004). Furthermore, three papers adapted psychological and/or educational theories as a basis for establishing their gamification approach. This is, for example, the case of Fuchs and Wolff (2016) whose gamified solution was based on two theories: cognitive load theory and Bloom's taxonomy. Finally, two papers proposed a new gamification method: Dubois and Tamburrelli (2013) presented a threephase process to gamify software development activities in students' projects, while Uskov and Sekar (2014) provided more general guidelines to incorporate gamification into SE education.

\subsubsection{RQ2.2 - Gamification elements}

RQ2.2 tries to identify the gaming dynamics, mechanics, and components used in each primary study. To answer RQ2.2, we first followed Werbach and Hunter's definition of dynamics, mechanics and components (Werbach and Hunter, 2012). We avoided inferring elements not explicitly mentioned in the primary studies and only recorded the ones definitely mentioned by the authors. As a result, we outlined all the gaming elements used by all primary studies, as shown in Fig. 10. Table B.6 in Appendix B lists further details on which gaming elements were used in which primary study. Leaderboards, points and levels were found to be the most frequently used gaming components with around $73 \%$ of the primary studies adopting one or more of these components in their gamified framework. Similarly, challenges, feedback and rewards were the most adopted mechanics, and progression was the most used dynamic.

During the analysis phase of this RQ we noticed that, with the exception of very few papers, the approach used to select which gamification elements to use for which purpose appears to be unclear. Nevertheless, some patterns in terms of which gamification elements were most often used together were identified. Fig. 11(a) and (b) show dendrograms illustrating gamification components and mechanics, respectively. The $y$-axis, represents, according to the Jaccard index (Everitt et al., 2001), how often particular elements are used together ( 1 -always-, 0 -never-). One of the most interesting patterns that we found was between points and leaderboards, as shown Fig. 11(a). While Fig. 10 illustrates that they are the most commonly used components, Fig. 11(a) tells us that they are also the most often combined gamification components. In fact, out of the 12 papers that implemented points in their gamified solution, 10 papers accompanied points with a leaderboard (see Table B.6 in Appendix B). This would appear to make sense as leaderboards are potentially a practical visual way of displaying the points earned by students. Fig. 11(b) also pinpoints patterns between game mechanics. For example, challenges and feedback were the two game mechanics most often used together. Seven papers combined the use of feedback with the use of challenges as a way of informing the students about how far they had advanced or how well they were doing in a certain challenge. For example, Fuchs and Wolff (2016) provided visual feedback to students about the progress of Java programming challenges; while Bartel and Hagel (2016) provided feedback to reflect how well students did in several challenges related to design patterns.

Additionally, to the patterns observed from Fig. 11, we were also interested in exploring whether there is an agreement on how each game dynamic or mechanic was represented in the primary studies. Generally speaking, the representation differs across different papers. For the game dynamic "progression", for example, some papers used more than one component (levels, badges and points) to represent progression (Matsubara and Silva, 2017). While, Chirila et al. (2016) used "points" as the only game component to represent progression. Moreover, challenges, for example, were represented using the game component "quests" in some papers (Bartel and Hagel, 2016; Matsubara and Silva, 2017), whereas they were customized to the subject or part of the course in other studies. For example, Fuchs and Wolff (2016) implemented Java-programming-customized challenges in three different ways: multiple-choice challenges, constructed response challenges, and programming challenges. Moreta et al. (2016) followed a similar approach of customizing challenges by presenting students with different risk management scenarios for analysis. Additionally, not all game dynamics or mechanics were always represented by a game component. For example, the mechanic "feedback" was im- 


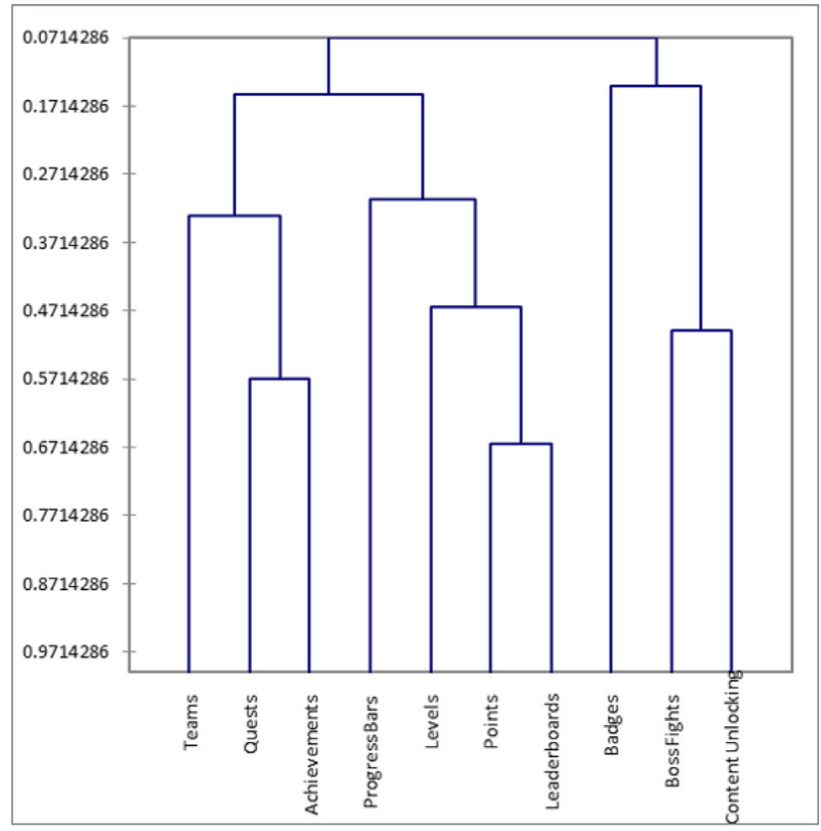

(a) Components Dendrogram

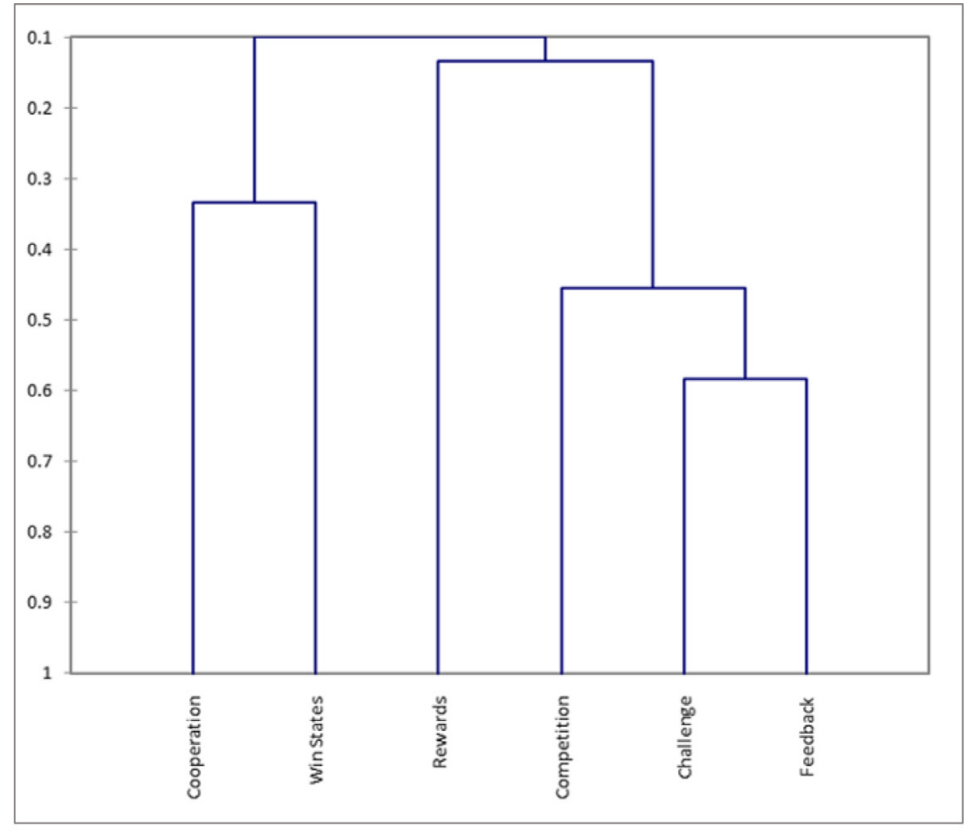

(b) Mechanics Dendrogram

Fig. 11. Patterns of how often gamification components and mechanics are used together.

plemented using a component in some cases and using a different technique in others. For example, Thomas and Berkling (2013) suggest that students be given immediate feedback through automatic grading of quizzes. Similarly, Raab (2012) follows the same principle by automatically displaying the right and wrong answers for students.

\subsubsection{RQ2.3 - Type of implementation}

RQ2.3 focuses on discovering the tools or platforms developed or used to implement gamification in SE education. The analysis of the collected data led to the following four categories:

1. A new gamification platform was developed: This includes studies that built a new standalone platform (mobile application or web application) that adopts gamification elements and design principles. For example, Bartel and Hagel (2014) developed "eMgage", a gamified mobile application to improve students' knowledge of basic SE concepts. "TeamFeed" by Singer and Schneider (2012) is another example of this category. TeamFeed is a web-based gamified application used to encourage continuous integration among students.

2. An existing gamified platform was used: This includes studies that utilize an existing gamified tool in their own SE course. For example, Sheth et al. (2013) used HALO, which employs gaming elements such as leaderboard, to engage students in completing Java programming assignments.

3. A gamification plug-in/extension to an existing non-gamified tool was used: This includes studies that either develop a plug-in for an open source non-gamified tool, or add gamification elements to extend a non-gamified tool. For example, Buisman and van Eekelen (2014) modified an existing open source project management tool called "Redmine" to add gaming elements such as points and leaderboard to motivate students to use project management tools. Similarly, Gondova et al. (2016) extended an online education system, namely "ALEF", to integrate the gamification component "levels". Their aim was to increase students' engagement by creating what they call "rooms". Students are required to answer a series of questions

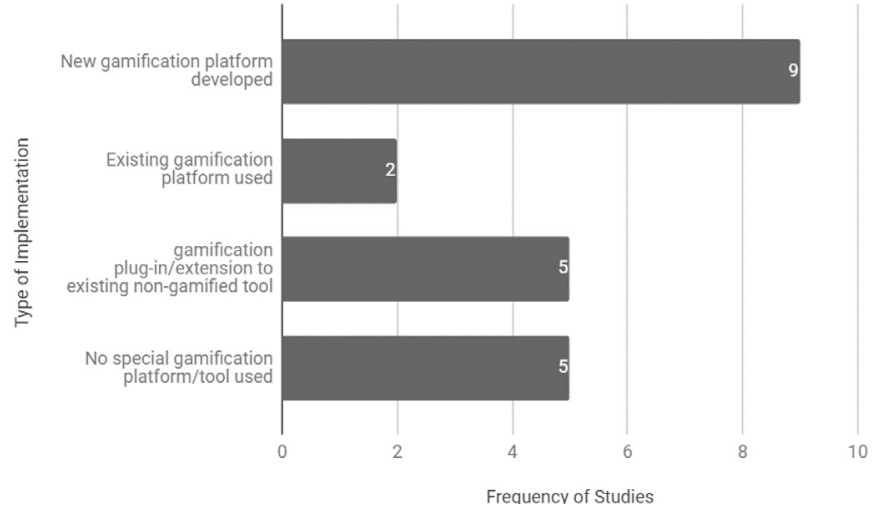

Fig. 12. Distribution of primary studies by type of implementation.

in each room in order to open the door to the next room and move on.

4. No special gamified or non-gamified tool was used: This includes studies that integrate gamification without using a special gamified tool or extending a non-gamified tool. For example, Akpolat and Slany (2014) designed challenges for students to solve in the field of extreme programming where the winning team would receive the challenge cup. The challenges were not supported by any special gamification tool. Another example is Laskowski (2015) who implemented a leaderboard by simply making a Google spreadsheet accessible for students to compare their scores.

Each primary study was classified under the above categories as illustrated in Fig. 12 (Table B.7 in Appendix B includes the particular tools that were considered in each category, if any). Clearly, most of the studies use some kind of tool to support gamification in their SE courses, and most authors opt for the creation of a new platform. 


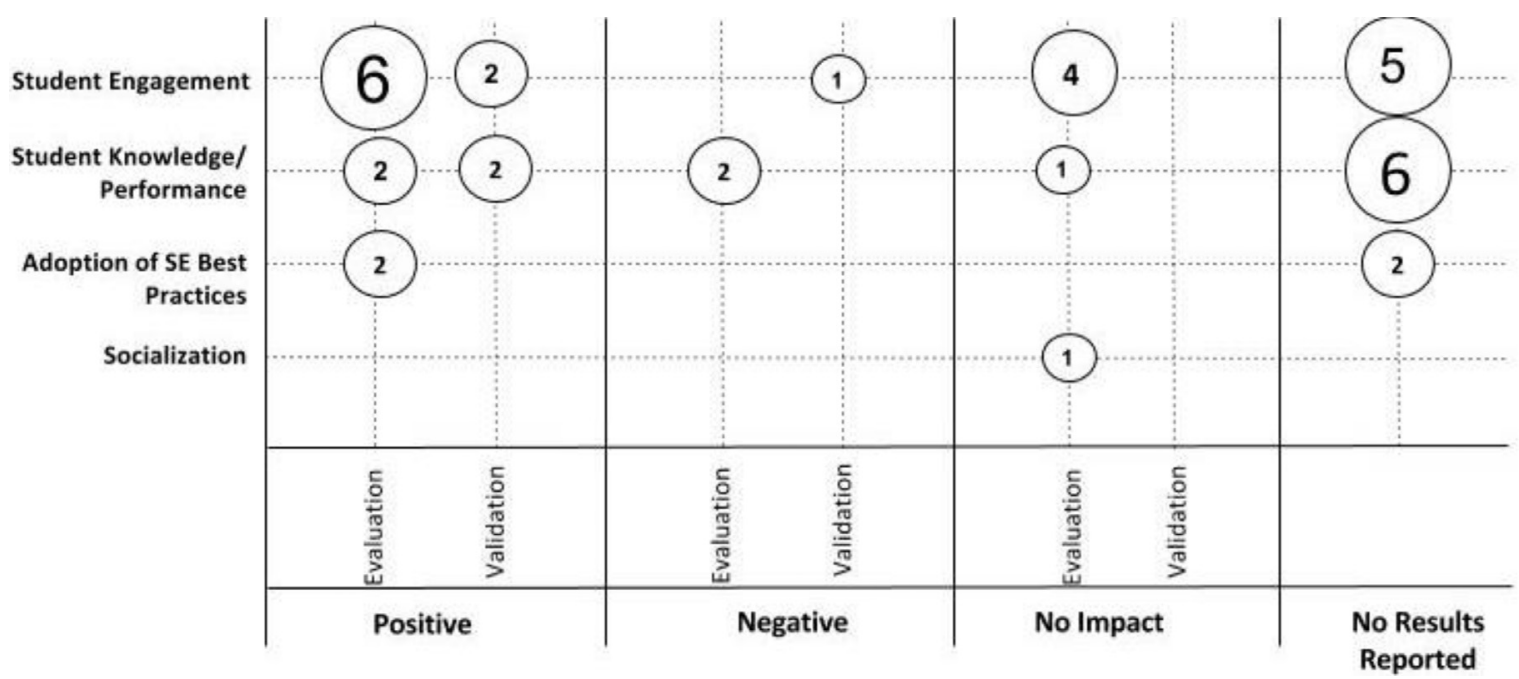

Fig. 13. Systematic map - gamification impact vs. research type.

\subsection{RQ3 - Evidential impact of gamification}

Fig. 13 synthesizes the frequency of primary studies according to the gamification purpose, the research type and the type of impact. According to the primary studies, the different purposes behind integrating gamification into SE courses can be grouped into four categories:

1. Increase student engagement: studies that gamified a SE course in order to stimulate and maintain students' interest in learning a specific subject or topic.

2. Improve students' knowledge or performance: studies that gamified a SE course in order to enhance the way students learn, make their learning process easier and more enjoyable to improve their overall performance (measured, for example, by grades, quality of developed products).

3. Encourage the use of SE best practices: studies that gamified a SE course in order to improve students' ability to apply SE best practices. Notice that in this case, the aim of the gamified experience is not focused on the learning process but on the application of the learned practices.

4. Improve students' team and social skills (i.e., socialization): studies that gamified a SE course in order to encourage team collaboration and coordination, leadership, sense of kinship, etc.

Fig. 13 shows the type of research in terms of how the evidence about the corresponding purpose was gathered (evaluation or validation studies). Finally, Fig. 13 also makes a distinction between impact type. "Positive Impact" represents primary studies that reported positive evidence about applying gamification for a particular purpose. "Negative Impact" represents primary studies that reported generally negative evidence about applying gamification. "No Impact" represents primary studies that reported no significant impact of applying gamification. Finally, "No Results Reported" represents primary studies that did not provide any quantitative or qualitative results about the impact of gamification. The specific references inside each group are shown in Table B.8 in Appendix B.

For some studies, the goal of integrating gamification was a mix of one or more of the above purposes and the reported results (positive impact, negative impact, no impact) differed depending on the purpose. Thus, the numbers in Fig. 13 do not add up to 21 (the number of primary studies).

Fig. 13 shows that most of the primary studies (18 papers) applied gamification with the aim of improving students' engagement. However, they did not all provide data about the resulting effect. For instance, five papers did not provide any data about students' engagement even though their authors explicitly mentioned this as one of the aims of their gamification experience. However, even though, due to the limited number of papers, we did not manage to get conclusive data about this effect, we clearly found that there were more positive than negative or no-impact results reported about students' engagement. Eight papers reported positive evidence (six by means of evaluation studies, i.e., in real class settings, and two by validation studies, i.e., pilot or experimental classes). On the other hand, only one paper reported a negative impact identified in a validation study, and four reported evaluations with no impact. Of the four evaluation studies that reported that gamification had no impact on students' engagement, Buisman and van Eekelen (2014), for example, reported that the feedback provided by students about the gamified experience showed a mix of positive and negative data, which they interpreted as meaning that "engagement and motivation were not significantly affected by gamification". About the particular indicators used to measure students engagement we find different possibilities, for example, Mora et al. (2016) reported a positive impact on students' engagement measured by the number of active students completing all assignments. However, Matsubara and Silva (2017) reported that students showed poor engagement with quests. This was measured as students not being interested in advancing to higher levels of quests.

Neither did the analysis provide clear evidence about the impact of gamification on improving students' knowledge, the second most referenced purpose. While only four papers reported an improvement in student performance (two evaluation studies and two validation studies), two validation studies reported that gamification had a negative impact on students' overall performance, and one more study concluded that gamification had no impact on improving the learning outcome for students. On the other hand, six papers failed to provide any evidence in this regard, even though it was considered as one of the aims of their gamification experience. Different indicators were used to measure students' knowledge. For example, Dubois and Tamburrelli (2013) reported an improvement in students' knowledge after assessing the quality of code written by students using metrics such as code duplication, number of bugs and test coverage. Bartel and Hagel (2016) reported an overall positive impact after analysing students' feedback. This feedback showed that a significantly high number of students stated that they were able to correctly apply the design patterns for unknown contexts. The negative impact reported 
by Berkling and Thomas (2013) and Laskowski (2015) was measured using students' final grades and students' feedback, respectively. Finally, Sheth et al. (2013) reported that gamification had no significant impact as students provided mixed feedback about the online gamified tool "HALO" not helping them to learn better.

Regarding the adoption of SE best practices, four papers dealt with this issue, yet only two provided any data, reporting positive results in a real class setting. Singer and Schneider (2012) were able to make students make smaller and more frequent changes to version control using a gamified approach. Similarly, Buisman and van Eekelen (2014) found that adding a competitive element encouraged students to use software project management tools such as version control. In sum, the perception of the impact of gamification on the adoption of SE best practices is positive, albeit inconclusive due to the small number of publications.

Finally, one primary study discussed the effect of gamification on improving students' collaboration and team skills (i.e., socialization) (Mora et al., 2016). However, the results of their experience showed that students' social skills did not improve. This was measured by observing the interactivity and communication among students in helping each other with the course assignments, which was found to be lacking.

\section{Discussion}

This study has highlighted that gamification in SE education is in its infancy, and there is an opportunity for detailed study and exploration. This is consistent with the fact that the first paper on gamification in SE education appeared in 2012, and most studies are published at conference venues instead of in journals. Even so, this study provides SE academics with a snapshot of the field that can be useful for anyone wanting to further explore and study the area at this early stage.

The literature of gamification in education have shown that gamification can be potentially effective in terms of supporting and motivating students leading to enhanced learning processes and outcomes (Dicheva et al., 2015). Our analysis shows that even though gamification in SE education may have potential, there are several important challenges and gaps in this field. Below we discuss the different challenges we identified from our analysis

- Need for empirical data. It is necessary to conduct more studies in the field to gather more data, thus generating more reliable results and conclusions for the community. In this respect, it is noteworthy that, unlike other areas of SE, most of the papers published to date report gamification experiences published in real class settings. While these papers report data, they do not provide enough information about the context of the SE course, students' background and so on for it to be possible to repeat the experience. Therefore, the results are hard to generalize.

Another important point is the type of metrics that the primary studies used. While some studies provide clear quantitative data and measurements to assess how gamification has affected a particular issue, others report the impact of gamification based on textual qualitative data, such as students' feedback, which can be prone to subjectivity. This also made it difficult to measure the significance of the impact of gamification beyond claims made by the primary paper authors. Examples of quantitative metrics used for measuring students' engagement are the total number of completed assignments (Laskowski, 2015), student's grade (Buisman and van Eekelen, 2014), the gamified tool usage/activity log (Gondova et al., 2016), or the number of students participating in a bonus or extra activity (Sheth et al., 2013). On the other hand, examples of qualitative indicators are students' feedback (Singer and Schneider, 2012) or surveys (Akpolat and Slany, 2014). Even though qualitative data are use- ful and provide key information about the gamified experience, they should be rounded out by quantitative metrics. This would provide a clear definition of what is considered to be an "improvement" in the context of gamification in SE education.

- Use of a gamification approach for SE education. As in the application of gamification to SE (Pedreira et al., 2015), another issue that demonstrates that gamification in SE education is in its infancy is the lack of a systematic approach for gamifying SE education, that is, a set of systematic steps that SE educators can follow to gamify their courses. Most of the primary studies implemented gamification by taking up some gamification ideas found in literature (in some cases with no prior evidence about their benefits) or experimenting with gaming elements to achieve their goals in SE education. Only a few papers followed a known gamification framework (e.g., MDA by Hunicke et al. (2004)) or a philosophical approach, whose general methods were effortfully adapted to the educational domain and, particularly, to the field of SE education.

On the other hand, the evidence gathered in this study shows that following an existing gamification framework provided no guarantee of the gamification experience achieving better results. For example, Matsubara and Silva (2017) gamified student projects and assignments based on a pre-defined gamification approach (Werbach and Hunter, 2012), yet they reported a negative impact on overall student engagement. Contrariwise, Singer and Schneider (2012) did not follow a structured approach, yet reported a positive impact on encouraging students to adapt SE best practices. Nevertheless, the two papers that designed their own structured approaches to gamify SE courses (Dubois and Tamburrelli, 2013; Uskov and Sekar, 2014) reported that gamification had a positive impact on students' engagement and knowledge improvement. Due to the small number of studies, no conclusive relation between following a structured gamification approach and creating a positive gamification experience can be established as yet. Additionally, if SE educators opt for following a gamification approach, they face the challenge of deciding whether follow an existing gamification framework or designing a new one, as there is no conclusive evidence on this issue either.

- Identification of gamification elements. From our study, we found that points and leaderboards were the most frequently adopted gaming elements individually and together. The same applies to the challenges and feedback mechanics. However, irrespective of whether or not a gamification approach was used, we were generally unable to identify the grounds for selecting these or other gamification elements. Leaderboards, points and levels were also identified as the most used elements in studies about gamification in education (Nah et al., 2014; Dicheva et al., 2015), and in the particular domain of SE (Pedreira et al., 2015). However, a detailed justification of the use of these elements for the different gamification purposes is also missing.

It is important in this respect to recall what authors like Fuchs and Wolff (2016) or (Robertson, 2010) refer to as "pointsification" or the simplistic use of gamification, that is, considering gamification as a way of just rewarding players with extrinsic motivation elements such as points, badges and leaderboards. As Robertson said, "pointisification takes the thing that is least essential to games and represents it as the core of the experience". Robertson argues that the use of these elements should not constitute the actual experience (e.g., learning); they should be seen and used as tools, along with other gamification elements, which trigger desired behaviors and help to achieve the main goal of the gamified experience. 
- Impact of gamification on the learning process. In some studies with negative results, we noticed that the gamified solution was not gradually incorporated to the curriculum or slowly introduced to the students. We take the view that this could have led to an extra cognitive workload for the students. This may have caused a sense of confusion or frustration which prevented them from fully understanding and enjoying the "game". Buisman and van Eekelen (2014) describe this idea as "highintensity gamification"; where new processes and activities are created as part of the new gamified experience. On the contrary, a "low-intensity gamification" approach introduces gamification gradually starting with no new activities and merely integrating gamification elements into existing processes. Besides, the introduction of gamification as a separate learning approach, when gamification is all about "integration in" or "combination with" the learning/teaching process, would just increment the noise in the learning process. Students would get distracted by new rules, new elements, new ways of learning, blurring the learning experience as a whole.

Our analysis has also led to the identification of several trends:

- Purpose of gamification in SE education. We found that most studies that provide data reported the positive impact of gamification with respect to several issues. The most positively affected aspect was student engagement, where gamification tended to help engage students in either a particular topic or a whole course. Students' overall performance and learning outcomes were also found to have more positive than negative results, and it also improved the adoption of SE best practices. As already mentioned, these are preliminary results that need to be further explored.

- Cost of gamification. It is interesting to see that gamification does not necessarily require the implementation of costly tools and frameworks. Although many papers developed a completely new gamified tool or designed an extension for an ordinary tool to support gamification, existing platforms or even the use of no special tools at all can be effective depending on the gamification purpose. For instance, the five studies that gamified a SE course without using any special tool reported positive results on either students' engagement or students' performance. On the contrary, no clear correlation could be established between developing a specialized tool and creating a successful gamified experience, because more than half of the studies that developed a special tool to gamify a SE course either did not validate or evaluate the effectiveness of the newly developed gamification platform/tool, or reported neutral results that showed no significant impact.

- Gamified SE process and educational activities. Most primary studies were found to incorporate multiple SE processes in their gamified experience. This is probably due to characteristics of the standard SE curriculum that comprises different stages of the software development life cycle. With the exception of a few papers that gamify courses focusing on only one SE area, such as requirements engineering or software testing, the tendency to gamify multiple SE areas may also be linked to the most frequently gamified educational activities: lectures and projects.

We found that the above challenges and trends can open up interesting research and action opportunities to enrich the field of gamification in SE education.

\section{Conclusion}

The literature on gamification in education shows that gamification has the potential to provide support for and motivate students, leading to enhanced learning processes and outcomes (Dicheva et al., 2015). Gamifying SE education could be of higher significance because of the idiosyncrasy of SE which involves frequent, complex, or repetitive tasks. SE educators are commonly faced with the challenge of students being unenthusiastic about learning complex SE concepts and problems. In this context, gamification is a recent but rapidly growing phenomenon worth of research and study.

Our systematic mapping has identified 21 primary papers in the field. This number is not huge, but it is consistent with the novelty of the field. From these papers, $77 \%$ provide empirical data about their experience with gamification (either evaluation or validation), resulting more positive than negative or no impacting results. However, those results cannot be conclusive due to small number of primary studies. Nevertheless, such results do provide a good overview of the field and have highlighted interesting issues as groundwork for further research in this area.

From our analysis, we identified a set of challenges and trends in SE education gamification. The challenges mainly focus on the need for both quantitative and qualitative data to show the benefits of gamification and help SE educators decide how to address gamification in terms of which approach to follow and which gamification elements to consider. Note that some of these challenges are not circumscribed merely to the SE education domain, but have also been found to apply to both SE gamification and gamification in other fields. Remember, for example, Gartner's warning that about $80 \%$ of gamified applications will fail to meet business objectives, mainly because processes have been inappropriately gamified (Gartner, 2012).

We should stress the need for more empirical research to arrive at reliable results about the effectiveness, benefits, and drawbacks of gamifying SE education. Even though there are more primary studies suggesting that gamification has a positive impact than all the papers that found it had no impact or negative impact combined, the difference is not yet significant due to the small sample size. Further research should be conducted to explore the impact of gamification on the learning process of particular SE lifecycle processes like software requirements or design, which were poorly addressed, or project planning, which was not addressed at all by the literature. Additionally, the lack of gender statistics in the SE education gamification literature makes it difficult to validate the hypothesis that women might be generally less interested in games. This might have an influence on the impact of gamification within the female SE student population.

Another issue that is worth investigating is the design of a systematic methodology to adopt gamification in SE education. In our opinion, a process should be gamified according to a series of steps with clear objectives and goals to achieve better results and improve performance, as suggested in the existing literature that we found on gamification. The lack of a systematic approach for gamifying SE education makes most proposals identified in the literature immature and difficult to replicate successfully in different contexts.

Furthermore, there are other approaches for improving SE education, such as large group-based projects for solving realistic problems. It might be interesting to discuss and compare the benefits of these approaches with the advantages of gamification. However, this would require a previous study to first identify the potential of these methods, which, to the best of our knowledge, has not yet been published.

Regarding the identified trends, we also found that gamification does not necessarily have to be costly in terms of technological solutions. However, the introduction of gamification elements does require a major effort on the part of educators to adapt the materials and the course workflow, even in the case of what some 
authors term low-intensity gamification, so as not to alter and disturb the students' learning process.

Finally, it is noteworthy that our mapping focused on papers that gamified SE courses by introducing gamification practices to improve the SE learning process. However, the literature also discusses the possibility of enriching SE curricula with gamification concepts (Uskov and Sekar, 2014; Unkelos-Shpigel and Hadar, 2016). Albeit outside the scope of our study, these papers present a complementary approach that can be used irrespectively of the gamification of the particular SE course in which they are taught. SE curricula should be thoroughly analysed to identify the SE courses in which gamification concepts should be taught, for example, software project management courses. Additionally, if gamification concepts are taught in combination with a gamification experience, care should be taken not to bias the results of this experience.

In sum, this systematic mapping points to several areas of research and action within an interesting area like gamification in SE education. We have found that, even though the definition of gamification is simple, its effective application in the educational area, and particularly to SE education, is not so straightforward: a number of different variables and decisions have to be carefully considered and dealt with.

\section{Appendix A. List of primary studies}

Akpolat, B. S. and Slany, W. (2014) 'Enhancing software engineering student team engagement in a high-intensity extreme programming course using gamification', 2014 IEEE 27th Conference on Software Engineering Education and Training, CSEE and T 2014 - Proceedings, pp. 149-153. doi: 10.1109/CSEET.2014.6816792.

Bartel, A. and Hagel, G. (2016) 'Gamifying the learning of design patterns in software engineering education', in IEEE Global Engineering Education Conference, EDUCON, pp. 1158-1162. doi: 10.1109/EDUCON.2016.7474534.

Bartel, a and Hagel, G. (2014) 'Engaging Students With a Mobile Game-Based Learning System in University Education', Global Engineering Education Conference (EDUCON), 2014 IEEE, (1), pp. 957-960. doi: 10.1109/EDUCON.2014.6826215.

Berkling, K. and Thomas, C. (2013) 'Gamification of a software engineering course and a detailed analysis of the factors that lead to its failure', 2013 International Conference on Interactive Collaborative Learning, ICL 2013, (September), pp. 525530. doi: 10.1109/ICL.2013.6644642.

Buisman, A. L. D. and van Eekelen, M. C. J. D. (2014) 'Gamification in educational software development', Proceedings of the Computer Science Education Research Conference on - CSERC '14, VV, pp. 9-20. doi: 10.1145/2691352.2691353.

Chirila, C. B., Raes, R. and Roland, A. (2016) 'Towards a generic gamification of sorting algorithms', 2016 12th IEEE International Symposium on Electronics and Telecommunications (ISETC), pp. 133-136. doi: 10.1109/ISETC.2016.7781075.

Dubois, D. J. and Tamburrelli, G. (2013) 'Understanding gamification mechanisms for software development', Proceedings of the 2013 9th Joint Meeting on Foundations of Software Engineering, (August 2013), p. 659. doi: 10.1145/2491411.2494589.

Fu, Y. and Clarke, P. (2016) 'Gamification-Based Cyber-Enabled Learning Environment of Software Testing', 2016 ASEE Annual Conference \& Exposition Proceedings. doi: 10.18260/p.27000.
Fuchs, M. and Wolff, C. (2016) 'Improving programming education through gameful, formative feedback', in 2016 IEEE Global Engineering Education Conference (EDUCON). IEEE, pp. 860-867. doi: 10.1109/EDUCON.2016.7474653.

Gondova, V., Labaj, M. and Bielikova, M. (2016) 'Personalized rooms based recommendation as a means for increasing students' activity', Lecture Notes in Computer Science (including subseries Lecture Notes in Artificial Intelligence and Lecture Notes in Bioinformatics), pp. 591-594. doi: 10.1007/9783-319-45153-4_70.

Ibanez, M.-B., Di-Serio, A. and Delgado-Kloos, C. (2014) 'Gamification for Engaging Computer Science Students in Learning Activities: A Case Study', IEEE Transactions on Learning Technologies, 7(3), pp. 291-301. doi: 10.1109/TLT.2014.2329293.

Kheirkhahzadeh, A. D., Sauer, C. S. and Fotaris, P. (2016) 'Practice makes perfect - Gamification of a competitive learning experience', in Proceedings of the European Conference on Games-based Learning, pp. 327335. Available at: https://www.scopus.com/inward/ record.uri?eid=2-s2.0-84997018007\&partnerID=40\&md5= 45c69fe771fc16a910e3d7a9f7958af0.

Laskowski, M. (2015) 'Implementing gamification techniques into university study path - A case study', IEEE Global Engineering Education Conference, EDUCON, 2015-April(March), pp. 582-586. doi: 10.1109/EDUCON.2015.7096028.

Matsubara, P. G. F. and Silva, C. L. C. Da (2017) 'Game Elements in a Software Engineering Study Group: A Case Study', 2017 IEEE/ACM 39th International Conference on Software Engineering: Software Engineering Education and Training Track (ICSESEET), (May), pp. 160-169. doi: 10.1109/ICSE-SEET.2017.8.

Mora, A., Planas, E. and Arnedo-Moreno, J. (2016) 'Designing Game-like Activities to Engage Adult Learners in Higher Education', Proceedings of the Fourth International Conference on Technological Ecosystems for Enhancing Multiculturality, pp. 755-762. doi: 10.1145/3012430.3012603.

Moreta, L. L., Gamboa, A. C. and Palacios, M. G. (2016) 'Implementing a Gamified Application for a Risk Management Course'. doi: 10.1109/ETCM.2016.7750858.

Raab, F. (2012) 'CodeSmellExplorer: Tangible exploration of code smells and refactorings', 2012 IEEE Symposium on Visual Languages and Human-Centric Computing (VL/HCC), pp. 261-262. doi: 10.1109/VLHCC.2012.6344544.

Sheth, S., Bell, J. and Kaiser, G. (2013) 'A competitivecollaborative approach for introducing software engineering in a CS2 class', Software Engineering Education Conference, Proceedings, pp. 41-50. doi: 10.1109/CSEET.2013.6595235.

Singer, L. and Schneider, K. (2012a) 'It was a bit of a race: Gamification of version control', 2012 2nd International Workshop on Games and Software Engineering: Realizing User Engagement with Game Engineering Techniques, GAS 2012 - Proceedings, pp. 5-8. doi: 10.1109/GAS.2012.6225927.

Thomas, C. and Berkling, K. (2013) 'Redesign of a Gamified Software Engineering Course Step 2 Scaffolding: Bridging the Motivation Gap', Interactive Collaborative Learning (ICL) ..., (September), pp. 525-530. Available at: http://ieeexplore. ieee.org/xpls/abs_all.jsp?arnumber=6644642.

Uskov, V. and Sekar, B. (2014) 'Gamification of software engineering curriculum', 2014 IEEE Frontiers in Education Conference (FIE) Proceedings, pp. 1-8. doi: 10.1109/FIE.2014.7044098. 


\section{Appendix B. Detailed information about primary studies}

Table B.1

Distribution of primary studies by research type.

\begin{tabular}{|c|c|c|}
\hline Research type & Primary studies & Total \\
\hline Evaluation research & $\begin{array}{l}\text { Singer and Schneider, 2012b; Sheth et al., 2013; } \\
\text { Berkling and Thomas, 2013; Dubois and } \\
\text { Tamburrelli, 2013; Akpolat and Slany, 2014; } \\
\text { Buisman and van Eekelen, 2014; Laskowski, } \\
\text { 2015; Bartel and Hagel, 2016; Fu and Clarke, } \\
\text { 2016; Gondova et al., 2016; Kheirkhahzadeh } \\
\text { et al., 2016; Mora et al., 2016 }\end{array}$ & 12 \\
\hline Validation research & $\begin{array}{l}\text { Ibanez et al., 2014; Uskov and Sekar, 2014; } \\
\text { Moreta et al., 2016; Matsubara and Silva, } 2017\end{array}$ & 4 \\
\hline Solution proposal & $\begin{array}{l}\text { Raab, 2012; Thomas and Berkling, 2013; Bartel } \\
\text { and Hagel, 2014; Chirila et al., 2016; Fuchs and } \\
\text { Wolff, } 2016\end{array}$ & 5 \\
\hline
\end{tabular}

Table B.2

Distribution of primary studies by course type.

\begin{tabular}{lll}
\hline Course type & Primary studies & Total \\
\hline Traditional SE Course & Raab, 2012; Singer and Schneider, 2012; & 15 \\
(No Online Support) & Sheth et al., 2013; Dubois and Tamburrelli, & \\
& 2013; Akpolat and Slany, 2014; Bartel and & \\
& Hagel, 2014; Uskov and Sekar, 2014; Bartel & \\
& and Hagel, 2016; Buisman and van Eekelen, & \\
& 2014; Ibanez et al., 2014; Laskowski, 2015; \\
& Moreta et al., 2016; Fuchs and Wolff, 2016; & \\
& Kheirkhahzadeh et al., 2016; Matsubara & \\
& and Silva, 2017 & \\
& Mora et al., 2016 & 1 \\
Online Course & Berkling and Thomas, 2013; Thomas and & 5 \\
Blended Course & Berkling, 2013; Chirila et al., 2016; Fu and & \\
& Clarke, 2016; Gondova et al., 2016 & \\
\hline
\end{tabular}

Table B.4

Distribution of primary studies by the gamified SE process.

\begin{tabular}{|c|c|c|}
\hline SE Process & Primary studies & Total \\
\hline Software Construction & $\begin{array}{l}\text { Ibanez et al., 2014; Chirila } \\
\text { et al., 2016; Fuchs and Wolff, } \\
\text { 2016; Kheirkhahzadeh et al., } \\
2016\end{array}$ & 4 \\
\hline Software Configuration & Singer and Schneider, 2012 & 1 \\
\hline Software Requirements & Mora et al., 2016 & 1 \\
\hline Software Design & Bartel and Hagel, 2016 & 1 \\
\hline $\begin{array}{c}\text { Software Process } \\
\text { Improvement }\end{array}$ & $\begin{array}{l}\text { Dubois and Tamburrelli, 2013; } \\
\text { Akpolat and Slany, 2014; } \\
\text { Buisman and van Eekelen, } 2014\end{array}$ & 3 \\
\hline Software Risk & Moreta et al., 2016 & 1 \\
\hline Software Testing & $\begin{array}{l}\text { Sheth et al., 2013; Fu and } \\
\text { Clarke, } 2016\end{array}$ & 2 \\
\hline Software Maintenance & Raab, 2012 & 1 \\
\hline Multiple SE Processes & $\begin{array}{l}\text { Berkling and Thomas, 2013; } \\
\text { Thomas and Berkling, 2013; } \\
\text { Bartel and Hagel, 2014; Uskov } \\
\text { and Sekar, 2014; Laskowski, } \\
\text { 2015; Gondova et al., 2016; } \\
\text { Matsubara and Silva, } 2017\end{array}$ & 7 \\
\hline
\end{tabular}

Table B.5

Distribution of primary studies by gamification approach.

\begin{tabular}{ll}
\hline $\begin{array}{l}\text { Type of Gamification } \\
\text { approach followed }\end{array}$ & Primary studies \\
\hline $\begin{array}{l}\text { Existing gamification } \\
\text { approach }\end{array}$ & $\begin{array}{l}\text { Ibanez et al., 2014; Bartel and Hagel, 2016; } \\
\text { Mora et al., 2016; Moreta et al., 2016; } \\
\text { Matsubara and Silva, 2017 }\end{array}$ \\
$\begin{array}{l}\text { Psychological and } \\
\text { educational theories } \\
\text { adapted as gamification } \\
\text { approach }\end{array}$ & Fuchs and Wolff, 2016 \\
$\begin{array}{l}\text { New gamification } \\
\text { approach }\end{array}$ & $\begin{array}{l}\text { Dubois and Tamburrelli, 2013; Uskov and } \\
\text { No formal or structured } \\
\text { approach }\end{array}$ \\
$\begin{array}{l}\text { Sekar, 2014 } \\
\text { Raab, 2012; Singer and Schneider, 2012b; Sheth } \\
\text { et al., 2013; Thomas and Berkling, 2013; Bartel } \\
\text { and Hagel, 2014; Buisman and van Eekelen, }\end{array}$ \\
2014; Laskowski, 2015; Fu and Clarke, 2016; \\
Gondova et al., 2016; Kheirkhahzadeh et al., \\
2016 \\
\hline
\end{tabular}

Table B.3

Distribution of primary studies by the gamified educational activity.

\begin{tabular}{lll}
\hline Educational activity & Primary studies & Total \\
\hline Lectures & Raab, 2012; Berkling and Thomas, 2013; & 10 \\
& Thomas and Berkling, 2013; Bartel and Hagel, & \\
& 2014; Ibanez et al., 2014; Uskov and Sekar, \\
& 2014; Chirila et al., 2016; Fu and Clarke, 2016; & \\
& Gondova et al., 2016; Moreta et al., 2016 & \\
& Uskov and Sekar, 2014; Bartel and Hagel, 2016; & 4 \\
Lab Sessions & Fuchs and Wolff, 2016; Kheirkhahzadeh et al., & \\
2016 & 5 \\
Shsignments & Laskowski, 2015; Mora et al., 2016; Matsubara & \\
& and Silva, 2017 \\
Projects & Tinger and Schneider, 2012; Dubois and & 7 \\
& Bumburrelli, 2013; Akpolat and Slany, 2014; & \\
& Sekar, 2014; Laskowski, 2015; Matsubara and \\
& Silva, 2017 & \\
\hline
\end{tabular}


Table B.6

Gamification elements used by primary studies.

\begin{tabular}{|c|c|c|c|}
\hline \multicolumn{2}{|l|}{ Game elements } & \multirow{2}{*}{$\begin{array}{l}\text { Primary studies } \\
\text { Bartel and Hagel, 2016; Matsubara and Silva, } 2017\end{array}$} & \multirow{2}{*}{$\frac{\text { Total }}{2}$} \\
\hline Dynamics & Narrative & & \\
\hline & Progression & $\begin{array}{l}\text { Uskov and Sekar, 2014; Bartel and Hagel, 2016; Chirila et al., 2016; } \\
\text { Matsubara and Silva, } 2017\end{array}$ & 4 \\
\hline & Emotions & Bartel and Hagel, 2016 & 1 \\
\hline & Relationships & Bartel and Hagel, 2016 & 1 \\
\hline & Constraints & Bartel and Hagel, 2016 & 1 \\
\hline \multirow[t]{6}{*}{ Mechanics } & Challenge & $\begin{array}{l}\text { Raab, 2012; Berkling and Thomas, 2013; Dubois and Tamburrelli, 2013; } \\
\text { Akpolat and Slany, 2014; Uskov and Sekar, 2014; Bartel and Hagel, 2016; } \\
\text { Fuchs and Wolff, 2016; Kheirkhahzadeh et al., 2016; Moreta et al., 2016; } \\
\text { Matsubara and Silva, 2017 }\end{array}$ & 10 \\
\hline & Competition & $\begin{array}{l}\text { Berkling and Thomas, 2013; Dubois and Tamburrelli, 2013; Uskov and } \\
\text { Sekar, 2014; Laskowski, 2015; Bartel and Hagel, 2016; Moreta et al., 2016; } \\
\text { Matsubara and Silva, } 2017\end{array}$ & 7 \\
\hline & Cooperation & $\begin{array}{l}\text { Thomas and Berkling, 2013; Bartel and Hagel, 2016; Matsubara and } \\
\text { Silva, } 2017\end{array}$ & 3 \\
\hline & Feedback & $\begin{array}{l}\text { Raab, 2012; Singer and Schneider, 2012b; Berkling and Thomas, 2013; } \\
\text { Thomas and Berkling, 2013; Uskov and Sekar, 2014; Bartel and Hagel, 2016; } \\
\text { Fuchs and Wolff, 2016; Moreta et al., 2016; Matsubara and Silva, } 2017\end{array}$ & 9 \\
\hline & Rewards & $\begin{array}{l}\text { Dubois and Tamburrelli, 2013; Sheth et al., 2013; Akpolat and Slany, 2014; } \\
\text { Buisman and van Eekelen, 2014; Bartel and Hagel, 2016; Fu and Clarke, } \\
\text { 2016; Mora et al., 2016; Matsubara and Silva, } 2017\end{array}$ & 8 \\
\hline & Win states & Bartel and Hagel, 2016 & 1 \\
\hline \multirow[t]{10}{*}{ Components } & Points & $\begin{array}{l}\text { Sheth et al., 2013; Berkling and Thomas, 2013; Bartel and Hagel, 2014, } \\
\text { 2016; Uskov and Sekar, 2014; Buisman and van Eekelen, 2014; Laskowski, } \\
\text { 2015; Chirila et al., 2016; Fu and Clarke, 2016; Fuchs and Wolff, 2016; } \\
\text { Moreta et al., 2016; Matsubara and Silva, 2017 }\end{array}$ & 12 \\
\hline & Badges & $\begin{array}{l}\text { Bartel and Hagel, 2014; Ibanez et al., 2014; Uskov and Sekar, 2014; } \\
\text { Laskowski, 2015; Fu and Clarke, 2016; Matsubara and Silva, } 2017\end{array}$ & 6 \\
\hline & Levels & $\begin{array}{l}\text { Singer and Schneider, 2012; Berkling and Thomas, 2013; Sheth et al., 2013; } \\
\text { Uskov and Sekar, 2014; Bartel and Hagel, 2016; Fuchs and Wolff, 2016; } \\
\text { Gondova et al., 2016; Moreta et al., 2016; Matsubara and Silva, } 2017\end{array}$ & 9 \\
\hline & Leaderboards & $\begin{array}{l}\text { Singer and Schneider, 2012; Sheth et al., 2013; Berkling and Thomas, 2013; } \\
\text { Bartel and Hagel, 2014, 2016; Uskov and Sekar, 2014; Buisman and van } \\
\text { Eekelen, 2014; Ibanez et al., 2014; Laskowski, 2015; Fu and Clarke, 2016; } \\
\text { Kheirkhahzadeh et al., 2016; Moreta et al., 2016; Matsubara and Silva, } 2017\end{array}$ & 13 \\
\hline & Progress bars & $\begin{array}{l}\text { Berkling and Thomas, 2013; Sheth et al., 2013; Moreta et al., 2016; } \\
\text { Matsubara and Silva, } 2017\end{array}$ & 4 \\
\hline & Quests & $\begin{array}{l}\text { Sheth et al., 2013; Uskov and Sekar, 2014; Bartel and Hagel, 2016; Mora } \\
\text { et al., 2016; Matsubara and Silva, } 2017\end{array}$ & 5 \\
\hline & Achievements & $\begin{array}{l}\text { Berkling and Thomas, 2013; Sheth et al., 2013; Ibanez et al., 2014; Uskov } \\
\text { and Sekar, 2014; Bartel and Hagel, 2016; Matsubara and Silva, } 2017\end{array}$ & 6 \\
\hline & Boss fights & Matsubara and Silva, 2017 & 1 \\
\hline & Content unlocking & Gondova et al., 2016; Matsubara and Silva, 2017 & 2 \\
\hline & Teams & Bartel and Hagel, 2016; Matsubara and Silva, 2017 & 2 \\
\hline
\end{tabular}

Table B.7

Types of gamification implementation in primary studies.

\begin{tabular}{|c|c|c|c|}
\hline Type of implementation & \# & Reference papers & Notes \\
\hline $\begin{array}{l}\text { New gamification platform/tool } \\
\text { developed }\end{array}$ & 9 & $\begin{array}{l}\text { Bartel and Hagel, } 2014 \\
\text { Berkling and Thomas, } 2013 \\
\text { Chirila et al., } 2016 \\
\text { Fu and Clarke, } 2016 \\
\text { Fuchs and Wolff, } 2016 \\
\text { Ibanez et al., } 2014 \\
\text { Moreta et al., } 2016 \\
\text { Raab, } 2012 \\
\text { Singer and Schneider, } 2012\end{array}$ & $\begin{array}{l}\text { Tool: eMgage } \\
\text { No tool name was provided } \\
\text { No tool name was provided } \\
\text { Tool: WReSTT-CyLE } \\
\text { Tool: Classgame } \\
\text { Tool: Q-Learning-G } \\
\text { No tool name was provided } \\
\text { Tool: CodeSmellExplorer } \\
\text { Tool: TeamFeed }\end{array}$ \\
\hline Existing gamification platform/tool used & 2 & $\begin{array}{l}\text { Kheirkhahzadeh et al., } 2016 \\
\text { Sheth et al., } 2013\end{array}$ & $\begin{array}{l}\text { Tool: HackerRank } \\
\text { Tool: HALO }\end{array}$ \\
\hline Gamification plug-in/extension to existing non-gamified tool & 5 & $\begin{array}{l}\text { Buisman and van Eekelen, } 2014 \\
\text { Dubois and Tamburrelli, } 2013 \\
\text { Gondova et al., } 2016 \\
\text { Mora et al., } 2016 \\
\text { Thomas and Berkling, } 2013\end{array}$ & $\begin{array}{l}\text { Tool: Redmine } \\
\text { Tool: Sonar } \\
\text { Tool: ALEF } \\
\text { Tool: Trello } \\
\text { Tool: Mozilla Open badge plug-in with CourseSites }\end{array}$ \\
\hline No special gamification platform/tool used & 5 & $\begin{array}{l}\text { Akpolat and Slany, } 2014 \\
\text { Bartel and Hagel, } 2016 \\
\text { Laskowski, } 2015 \\
\text { Matsubara and Silva, } 2017 \\
\text { Uskov and Sekar, } 2014\end{array}$ & $\begin{array}{l}\text { Details not provided } \\
\text { Quests were sent by email } \\
\text { Poker chips used for awarding points } \\
\text { Tool: Moodle } \\
\text { Details not provided }\end{array}$ \\
\hline
\end{tabular}


Table B.8

Distribution of primary studies by gamification impact and research type.

\begin{tabular}{|c|c|c|c|}
\hline Aspect of impact & Type of impact & Evaluation & Validation \\
\hline \multirow[t]{3}{*}{ Students' engagement } & (positive) & $\begin{array}{l}\text { Akpolat and Slany, 2014; Laskowski, } \\
\text { 2015; Chirila et al., 2016; Gondova } \\
\text { et al., 2016; Kheirkhahzadeh et al., } \\
\text { 2016; Mora et al., } 2016\end{array}$ & Ibanez et al., 2014; Uskov and Sekar, 2014 \\
\hline & (negative) & - & Matsubara and Silva, 2017 \\
\hline & (no impact) & $\begin{array}{l}\text { Singer and Schneider, 2012; Sheth } \\
\text { et al., 2013; Buisman and van Eekelen, } \\
\text { 2014; Fu and Clarke, } 2016\end{array}$ & - \\
\hline Adoption of SE best practices & (positive) & $\begin{array}{l}\text { Singer and Schneider, 2012; Buisman } \\
\text { and van Eekelen, } 2014\end{array}$ & - \\
\hline \multirow[t]{3}{*}{ Knowledge /performance improvement } & (positive) & $\begin{array}{l}\text { Dubois and Tamburrelli, 2013; Bartel } \\
\text { and Hagel, } 2016\end{array}$ & Ibanez et al., 2014; Matsubara and Silva, 2017 \\
\hline & (negative) & $\begin{array}{l}\text { Berkling and Thomas, 2013; Laskowski, } \\
2015\end{array}$ & - \\
\hline & (no impact) & Sheth et al., 2013 & - \\
\hline Socialization & (no impact) & Mora et al., 2016 & - \\
\hline
\end{tabular}

\section{References}

Akpolat, B.S., Slany, W., 2014. Enhancing software engineering student team engagement in a high-intensity extreme programming course using gamification'. In: 2014 IEEE 27th Conference on Software Engineering Education and Training, CSEE and T 2014 - Proceedings, pp. 149-153 doi:10.1109/CSEET.2014.6816792.

Alabbadi, A.A., Qureshi, R.J., 2016. The proposed methods to improve teaching of software engineering. I.J. Mod. Educ. Comput. Sci. Mod. Educ. Comput. Sci. 7 (7), 13-21. doi:10.5815/ijmecs.2016.07.02.

Bacon, D.F, et al., 2012. Predicting your own effort. In: Proceedings of the 11th International Conference on Autonomous Agents and Multiagent Systems, (June), pp. 695-702. Available at: http://dash.harvard.edu/handle/1/8191221.

Barata, G, et al., 2013. Improving participation and learning with gamification. In: Proceedings of the First International Conference on Gameful Design, Research, and Applications - Gamification 2013, (October 2-4), pp. 10-17. doi:10.1145/2583008. 2583010.

Bartel, A., Hagel, G., 2016. Gamifying the learning of design patterns in software engineering education. In: IEEE Global Engineering Education Conference, EDUCON, pp. 1158-1162. doi:10.1109/EDUCON.2016.7474534.

Bartel, a, Hagel, G, 2014. Engaging students with a mobile game-based learning system in university education. In: Global Engineering Education Conference (EDUCON), 2014 IEEE, (1), pp. 957-960. doi:10.1109/EDUCON.2014.6826215.

Berkling, K., Thomas, C., 2013. Gamification of a software engineering course and a detailed analysis of the factors that lead to it's failure'. In: 2013 International Conference on Interactive Collaborative Learning, ICL 2013, (September), pp. 525530. doi:10.1109/ICL.2013.6644642.

Bíró, G.I., 2014. Didactics 2.0: a pedagogical analysis of gamification theory from a comparative perspective with a special view to the components of learning. In: Procedia - Social and Behavioral Sciences. Elsevier, B.V., 141, pp. 148-151. doi:10. 1016/j.sbspro.2014.05.027.

Borges, S. et al. (2014) 'A systematic mapping on gamification applied to education'. doi:10.1145/2554850.2554956.

Buisman, A.L.D., van Eekelen, M.C.J.D., 2014. Gamification in educational software development. In: Proceedings of the Computer Science Education Research Conference on - CSERC '14, VV, pp. 9-20. doi:10.1145/2691352.2691353.

Caponetto, I, Earp, J, Ott, M, 2014. Gamification and education: a literature review. In: European Conference on Games Based Learning, p. 50.

Chirila, C.B., Raes, R., Roland, A., 2016. Towards a generic gamification of sorting algorithms. In: 2016 12th IEEE International Symposium on Electronics and Telecommunications (ISETC), pp. 133-136. doi:10.1109/ISETC.2016.7781075.

Choi, E., 2013. Applying inverted classroom to software engineering education. Int. J. e-Educ., e-Bus., e-Manage. e-Learn. 3 (2). doi:10.7763/IJEEEE.2013.V3.205.

Connolly, T.M., Stansfield, M., Hainey, T., 2007. An application of games-based learning within software engineering. Br. J. Educ. Technol. 38 (3), 416-428. doi:10. $1111 / j .1467-8535.2007 .00706 . x$

Cruzes, D.S., Dyba, T., 2011. Recommended steps for thematic synthesis in software engineering. In: 2011 International Symposium on Empirical Software Engineering and Measurement, (7491), pp. 275-284 doi:10.1109/ESEM.2011.36.

Davey, B., Tatnall, A., 2008. Where will professional software engineering education go next? In: Learning to Live in the Knowledge Society. Springer US, Boston, MA, pp. 185-192. doi:10.1007/978-0-387-09729-9_29.

Davis, A., 1993. Software lemmingineering. IEEE Softw 10, 79-81.

Deterding, S, et al., 2011. From game design elements to gamefulness. In: Proceedings of the 15th International Academic MindTrek Conference on Envisioning Future Media Environments - MindTrek '11. New York, USA. ACM Press, p. 9. doi: $10.1145 / 2181037.2181040$

Dicheva, D, et al., 2015. Gamification in education: a systematic mapping study. Educ. Technol. Soc. 18 (3), 75-88.
Domínguez, A, et al., 2013. Gamifying learning experiences: practical implications and outcomes. Comput. Educ. Pergamon 63, 380-392. doi:10.1016/j.compedu. 2012.12.020.

Dubois, D.J., Tamburrelli, G., 2013. Understanding gamification mechanisms for software development. In: Proceedings of the 2013 9th Joint Meeting on Foundations of Software Engineering, (August 2013), p. 659. doi:10.1145/2491411.2494589.

Everitt, B.S., Landau, S., Leese, M., 2001. Cluster Analysis, 4th ed. Arnold, London s.n. Fernandes, J, et al., 2012. IThink: a game-based approach towards improving collaboration and participation in requirement elicitation. In: Procedia Computer Science. Elsevier, pp. 66-77. doi:10.1016/j.procs.2012.10.059.

Fu, Y., Clarke, P., 2016. Gamification-based cyber-enabled learning environment of software testing. In: 2016 ASEE Annual Conference \& Exposition Proceedings doi: $10.18260 /$ p. 27000 .

Fuchs, M., Wolff, C., 2016. Improving programming education through gameful, formative feedback. In: 2016 IEEE Global Engineering Education Conference (EDUCON). IEEE, pp. 860-867. doi:10.1109/EDUCON.2016.7474653.

García, F, et al., 2017. A framework for gamification in software engineering. J. Syst. Software 132, 21-40. doi:10.1016/j.jss.2017.06.021.

Gartner, 2012. Gartner Says by 2014, 80 Percent of Current Gamified Applications will fail to Meet Business Objectives Primarily due to Poor Design. [Online] [Accessed September 2017].

Gondova, V., Labaj, M., Bielikova, M., 2016. Personalized rooms based recommendation as a mean for increasing students' activity. In: Lecture Notes in Computer Science (including subseries Lecture Notes in Artificial Intelligence and Lecture Notes in Bioinformatics), pp. 591-594 doi:10.1007/978-3-319-45153-4 70.

Grant, E., Helps, W., 2012. Enhancing teaching \& learning of software engineering in an international environment. GSTF J. Comput. 2 (1). Available at: http: //dl6.globalstf.org/index.php/joc/article/viewFile/669/700. (Accessed: 12 October 2017).

GSwE. Curriculum Guidelines for Graduate Degree Programs in Software Engineering [Online] Available at:. https://www.acm.org/binaries/content/assets education/gsew2009.pdf.

Gustafsson, A., Katzeff, C., Bang, M., 2009. Evaluation of a pervasive game for domestic energy engagement among teenagers. Comput. Entertainment 7 (4), 1. doi:10.1145/1658866.1658873.

Hakulinen, L., Auvinen, T., 2014. The effect of gamification on students with different achievement goal orientations. In: 2014 International Conference on Teaching and Learning in Computing and Engineering. IEEE, pp. 9-16. doi:10.1109/LaTiCE 2014.10.

Hamari, J., Koivisto, J., Sarsa, H., 2014. Does gamification work? - A literature review of empirical studies on gamification'. In: Proceedings of the Annual Hawaii International Conference on System Sciences, pp. 3025-3034. doi:10.1109/HICSS. 2014.377.

Hanus, M.D., Fox, J., 2015. Assessing the effects of gamification in the classroom: a longitudinal study on intrinsic motivation, social comparison, satisfaction, effort, and academic performance. In: Comput. Educ. Elsevier Ltd, 80, pp. 152-161. doi:10.1016/j.compedu.2014.08.019.

Hazzan, O., Tomayko, J.E., 2005. Reflection and abstraction in learning software engineering's human aspects. Computer 38 (6), 39-45. doi:10.1109/MC.2005.200.

Hunicke, R., LeBlanc, M., Zubek, R., 2004. MDA: a formal approach to game design and game research. In: Workshop on Challenges in Game AI, pp. 1-4. doi: 10.1. 1.79.4561.

Ibanez, M.-B., Di-Serio, A., Delgado-Kloos, C., 2014. Gamification for engaging computer science students in learning activities: a case study. IEEE Trans. Learn Technol. 7 (3), 291-301. doi:10.1109/TLT.2014.2329293.

IEEE, 2014. Software Engineering Competency Model. IEEE Computer Society Available at: http://www.computer.org/web/pressroom/ software-engineering-competency-model-open-for-public-review. 
Johnson, L., Adams Becker, S., Estrada, V., Freeman, A., 2014. NMC Horizon Report: 2014 Higher Education Edition. The New Media Consortium, Austin, Texas.

Kapp, K.M., 2012. The Gamification of Learning and Instruction: Game-based Methods and Strategies for Training and Education, 1st edn. Pfeiffer \& Company.

Khandelwal, S., Sripada, S.K., Reddy, Y.R., 2017. Impact of gamification on code review process'. In: Proceedings of the 10th Innovations in Software Engineering Conference on - ISEC '17, pp. 122-126. doi:10.1145/3021460.3021474.

Kheirkhahzadeh, A.D., Sauer, C.S., Fotaris, P., 2016. Practice makes perfect - gamification of a competitive learning experience. In: Proceedings of the European Conference on Games-based Learning, pp. 327335. Available at: https://www.scopus.com/inward/record.uri?eid=2-s2. 0-84997018007\&partnerID=40\&md5=45c69fe771 fc16a910e3d7a9f7958afo.

Kitchenham, B, et al., 2005. An investigation of software engineering curricula. In: Journal of Systems and Software. Elsevier, pp. 325-335. doi:10.1016/j.jss.2004. 03.016

Laskowski, M., 2015. Implementing gamification techniques into university study path - a case study'. In: IEEE Global Engineering Education Conference, EDUCON, 2015-April (March), pp. 582-586. doi:10.1109/EDUCON.2015.7096028.

Lethbridge, T.C, et al., 2007. Improving software practice through education: challenges and future trends. Future Software Eng. 2007, 12-28. doi:10.1109/FOSE. 2007.13, FOSE'07, 2

Li, C, et al., 2013. Engaging computer science students through gamification in an online social network based collaborative learning environment. Int. J. Inf. Educ. Technol. 3 (1). doi:10.7763/IJIET.2013.V3.237.

Marques, M.R., Quispe, A., Ochoa, S.F., 2014. A systematic mapping study on practical approaches to teaching software engineering. In: 2014 IEEE Frontiers in Education Conference (FIE) Proceedings, 2015-February, pp. 1-8. doi:10.1109/FIE.2014. 7044277.

Matsubara, P.G.F., Silva, C.L.C.Da, 2017. Game elements in a software engineering study group: a case study. In: 2017 IEEE/ACM 39th International Conference on Software Engineering: Software Engineering Education and Training Track (ICSESEET), (May), pp. 160-169. doi:10.1109/ICSE-SEET.2017.8.

de Melo, A.A, et al., 2014. Version Control System Gamification: A Proposal to Encourage the Engagement of Developers to Collaborate in Software Projects. Springer, Cham, pp. 550-558. doi: 10.1007/978-3-319-07632-4_52.

Mendeley Mendeley. [Online] Available at:. https://www.mendeley.com/[Accessed December 2017].

Mora, A., Planas, E., Arnedo-Moreno, J., 2016. Designing game-like activities to engage adult learners in higher education. In: Proceedings of the Fourth International Conference on Technological Ecosystems for Enhancing Multiculturality, pp. 755-762. doi:10.1145/3012430.3012603.

Moreta, L.L., Gamboa, A.C. and Palacios, M.G. (2016) 'Implementing a Gamified application for a Risk Management Course'. doi:10.1109/ETCM.2016.7750858.

Nah, F.F.H, et al., 2014. Gamification of education: a review of literature. In: 1st International Conference on $\mathrm{HCI}$ in Business, HCIB 2014, 8527, pp. 401-409. doi:10.1007/978-3-319-07293-7.

Pedreira, O, et al., 2015. Gamification in software engineering â “" A systematic mapping. Inf. Software Technol. 57, 157-168. doi:10.1016/j.infsof.2014.08.007.

Pereira, P, et al., 2014. A Review of Gamification for Health-Related Contexts. Springer, Cham, pp. 742-753. doi:10.1007/978-3-319-07626-3_70.

Petersen, K., Feldt, R., 2008. Systematic mapping studies in software engineering. In: ... in Software Engineering, pp. 1-10. Available at: http://robertfeldt.net| publications/petersen_ease08_sysmap_studies_in_se.pdf.

Petersen, K., Vakkalanka, S., Kuzniarz, L., 2015. Guidelines for conducting systematic mapping studies in software engineering: an update. Inf. Software Technol. doi:10.1016/j.infsof.2015.03.007.
Qadir, M.M., Usman, M., 2011. Software engineering curriculum: a systematic mapping study. In: Software Engineering (MySEC), 2011 5th Malaysian Conference in, pp. 269-274. doi:10.1109/MySEC.2011.6140682.

Raab, F., 2012. CodeSmellExplorer: Tangible exploration of code smells and refactorings'. In: 2012 IEEE Symposium on Visual Languages and Human-Centric Computing (VL/HCC), pp. 261-262. doi:10.1109/VLHCC.2012.6344544

Robertson, M., 2010. Can't Play, Won't Play. [Online] [Accessed September 2017].

SE. Curriculum Guidelines for Undergraduate Degree Programs in Software Engineering [Online] Available at. doi: https://www.acm.org/binaries/content/assets/ education/se2014.pdf.

Sheth, S., Bell, J., Kaiser, G., 2013. A competitive-collaborative approach for introducing software engineering in a CS2 class'. In: Software Engineering Education Conference, Proceedings, pp. 41-50. doi:10.1109/CSEET.2013.6595235.

Singer, L., Schneider, K., 2012a. It was a bit of a race: gamification of version control'. In: 2012 2nd International Workshop on Games and Software Engineering: Realizing User Engagement with Game Engineering Techniques, GAS 2012 - Proceedings, pp. 5-8. doi:10.1109/GAS.2012.6225927.

Souza, M.R.D.A, et al., 2017. Games for learning: Bridging game-related education methods to software engineering knowledge areas. In: Proceedings - 2017 IEEE/ACM 39th International Conference on Software Engineering: Software Engineering and Education Track, ICSE-SEET 2017. IEEE, pp. 170-179. doi:10.1109/ ICSE-SEET.2017.17

Surakka, S., 2007. What subjects and skills are important for software developers. Commun. ACM (1 January) 73-78. doi:10.1145/1188913.1188920.

Thomas, C., Berkling, K., 2013. Redesign of a gamified software engineering course step 2 scaffolding: bridging the motivation gap. In: Interactive Collaborative Learning (ICL) ..., September, pp. 525-530. Available at: http://ieeexplore.ieee. org/xpls/abs_all.jsp?arnumber $=6644642$.

Unkelos-Shpigel, N., Hadar, I., 2016. Inviting everyone to play: gamifying collaborative requirements engineering. In: 5 th International Workshop on Empirical Requirements Engineering, EmpiRE 2015 - Proceedings, pp. 13-16. doi:10.1109/ EmpiRE.2015.7431301.

Uskov, V., Sekar, B., 2014. Gamification of software engineering curriculum. In: 2014 IEEE Frontiers in Education Conference (FIE) Proceedings, pp. 1-8. doi:10.1109/ FIE.2014.7044098.

Werbach, K., Hunter, D., 2012. The Gamification Toolkit: Dynamics, Mechanics, and Components for the Win. Wharton Digital Press.

Wieringa, R, et al., 2006. Requirements engineering paper classification and evaluation criteria: a proposal and a discussion. Requirements Eng. 11 (1), 102-107. doi:10.1007/s00766-005-0021-6.

Wingfield, C., 2012. All the World's a Game, and Business is a Player. The New York Times 23 December.

Witt, M., Scheiner, C., Robra-Bissantz, S., 2011. Gamification of online idea competitions: insights from an explorative case. Informatik P192, 1-15. doi: 10.1.1.259. 4820.

Wu, B., Wang, A.I., 2012. A guideline for game development-based learning: a literature review. Int. J. Comput. Games Technol. New York, NY, United States: Hindawi Publishing Corp., 2012, pp. 8:8-8:8. doi: 10.1155/2012/103710.

Zichermann, G., Cunningham, C., 2011. Gamification By design: Implementing Game Mechanics in Web and Mobile Apps. O'Reilly Media.

Zichermann, G., Linder, J., 2010. Game-based marketing: Inspire Customer Loyalty Through rewards, challenges, and Contests. Wiley. 
Manal M. Alhammad, MSc

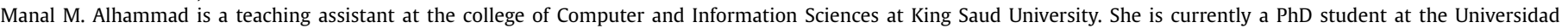

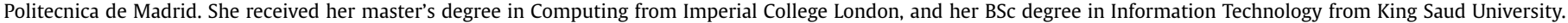
Her research interests include Software Engineering Education and Agile Development.

Ana M. Moreno, PhD

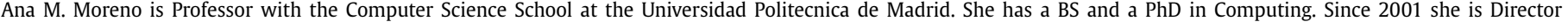

of the MSc in Software Engineering. Her research interests are Software Engineering Education, Software Usability and Agile Development. 